\title{
انعكاس الكفاءة الذاتية للمديرين في سلوكياتهم
}

\author{
الباحث حسين وليا حسين البين \\ وزارة التعليم العالي والبحث وليث العلمين \\ كلية الادارة والاقتصاد - جامعة بغذاد \\ أ. م.د. اظم جواد عبد سلمان

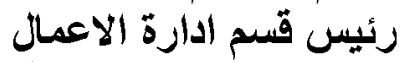

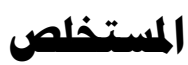

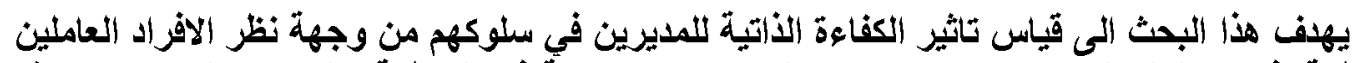

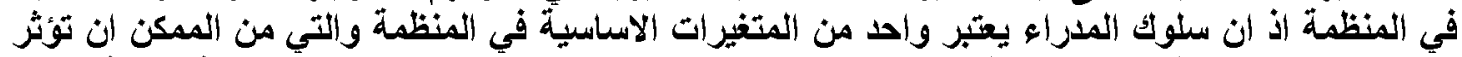

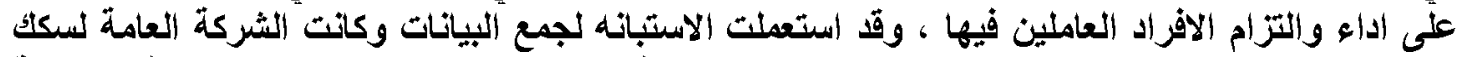

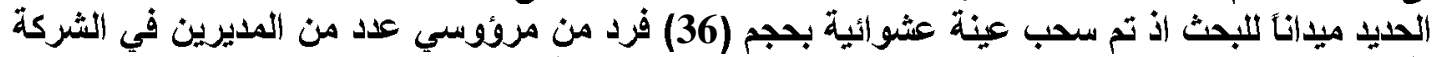

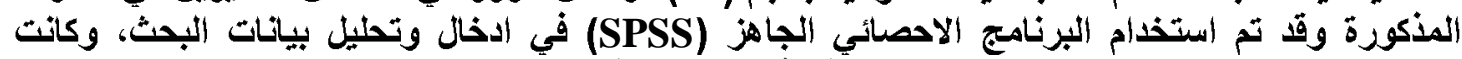

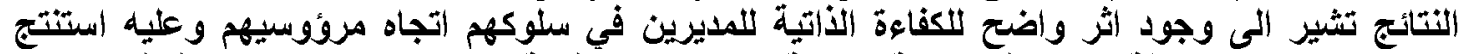

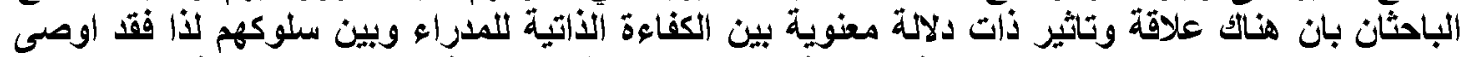

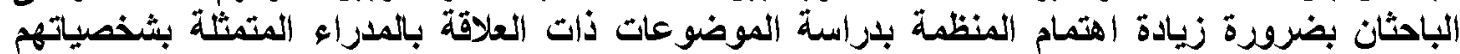

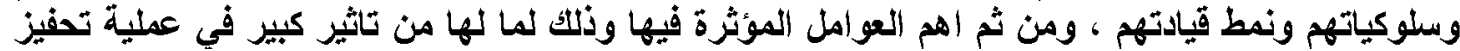

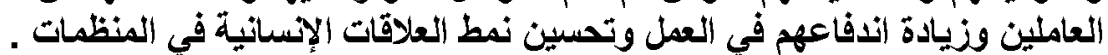

الإصلحات الرئيسية للبحث/ المدراء- الكفاعة الأتيةـ السلوكـ العاملين- المنظمة القيادة .

Afded

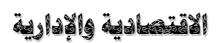

19

74 اله

$110-94$ illatis 
يعد المدير ونمطه السلوكي من العوامل المهمة التي تؤثر في قدرة المنظمة على تهئ تحقيق الهدافها

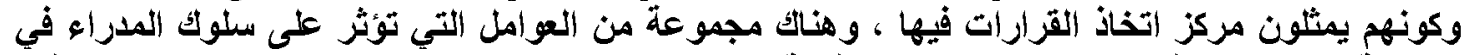

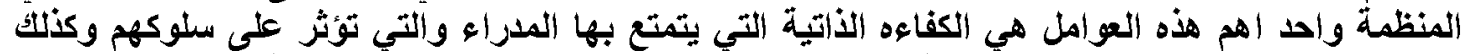

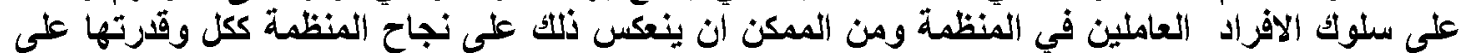

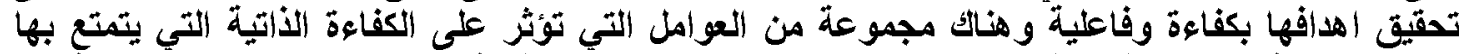

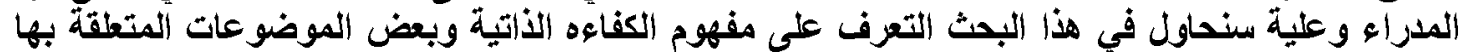

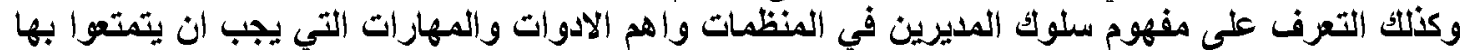

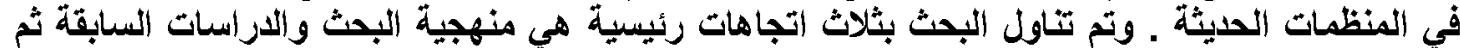
الجاتب النظري ، وكذلك الجاتب العملي والاستنتاجات والتوب التوصيات .

\section{المبحث الأول/ هنهجية البحث ودراسات سابقة}

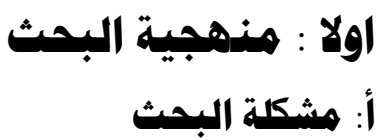

الشار الجدل الفكري الى ان هناك الك علاقة ما بين الكفايوه الأتية للمديرين وسلوكهم اتجاه العاملين داخل

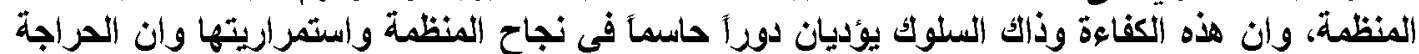

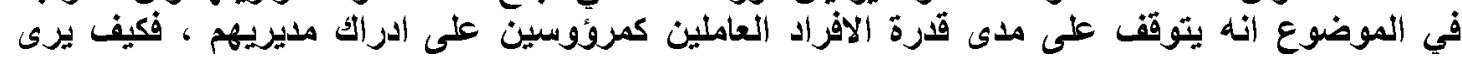

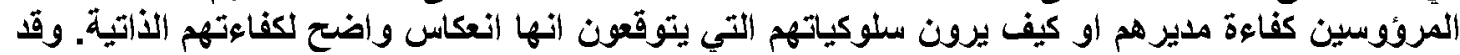

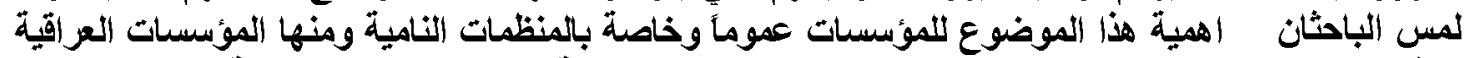

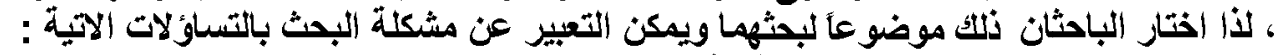

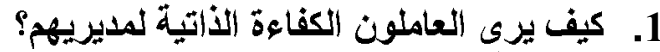

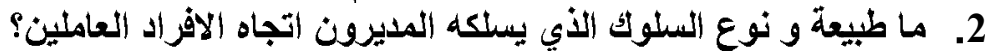
3. ما مستوى وطبيعة العلاقة والاثر بين الكفاءه الأتية للمديرين وسلوكهم اتجاه العاملين؟

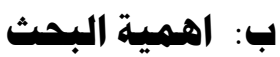

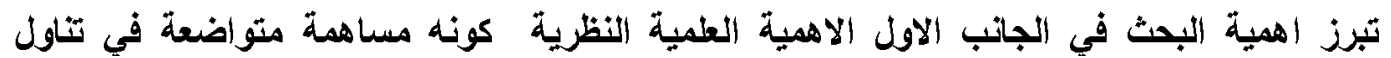

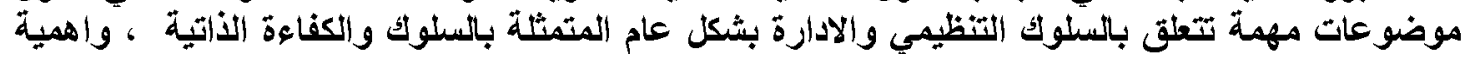

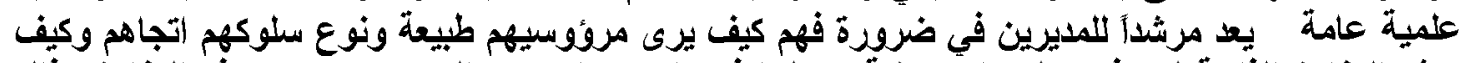

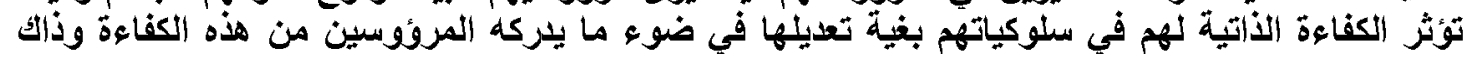
السلوك.

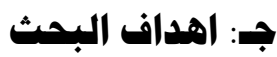

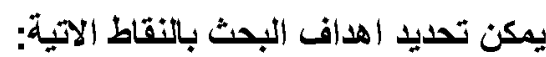

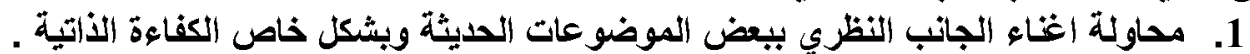

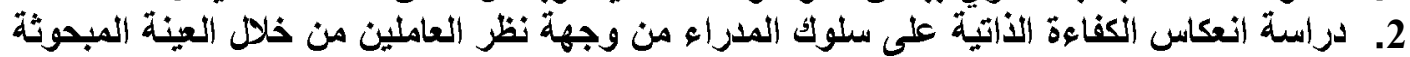

3. التعرف على بعض العوامل المؤثرة على الكفاءة الأتية للمدراء في العينة المبحوثة .

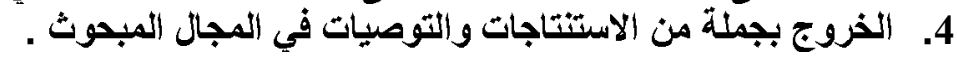

د: فرضية البحث

ينطلق البحث من فرضية اسناسية تنص على : " وجود علاقة ارتباط وتاثير ذات دلالة معنوية بين الكفاءة

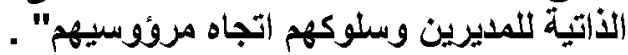




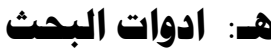

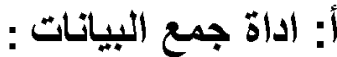

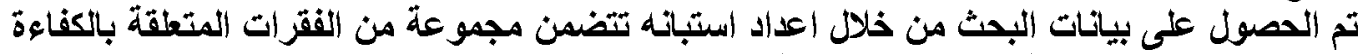

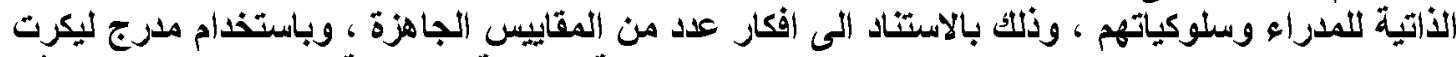

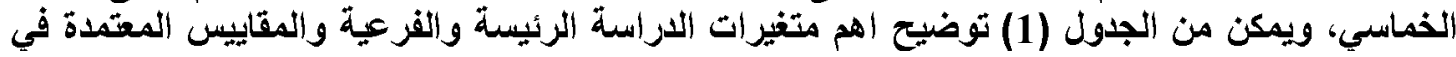

الجدول (1) متغيرات الاستبانه الرئيسية والفرعية والمقاييس المعتمدة في اعدادها

\begin{tabular}{|c|c|c|c|c|c|}
\hline المقاييس & الفقرات & المتغيرات الفرعية & نوع المتغير & الألمتغيرات & $ت$ \\
\hline \multirow{8}{*}{$\begin{array}{c}\text { Switzer et al : } \\
\text { 2005 } \\
\text { 2011: Sanda }\end{array}$} & $3-2-1$ & الكفاعة القردية والجماعية الأاتية & \multirow{3}{*}{ متفير مستثل } & \multirow{3}{*}{ الأكفاءة } & \multirow{3}{*}{1} \\
\hline & $\begin{array}{ll}6-5-4 \\
\end{array}$ & الكفاءة الاستراتيجية الذاتية & & & \\
\hline & $\begin{array}{l}9-8-7 \\
\end{array}$ & الكفاءة التنظيمية الذاتية & & & \\
\hline & 12-11-10 & السلو ك السلبي & \multirow{5}{*}{ (استجابي) تابع } & \multirow{5}{*}{ سلو المدراء } & \multirow{5}{*}{2} \\
\hline & 15-14-13 & السلوك الشعوري & & & \\
\hline & 18-17-16 & السلوك المشروط & & & \\
\hline & 21-20-19 & السلوك غير المسيطر علية & & & \\
\hline & 24-23-22 & السلوك الجماعي & & & \\
\hline
\end{tabular}

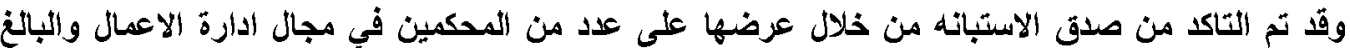

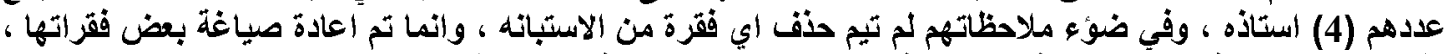

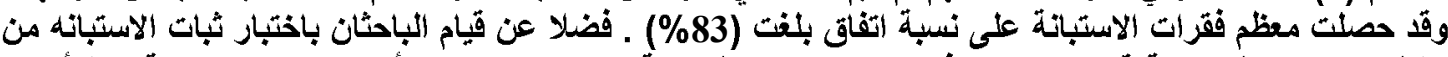

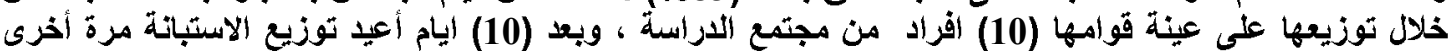

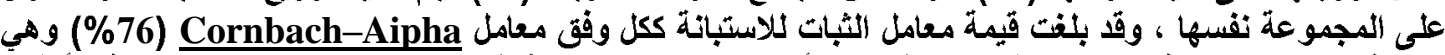

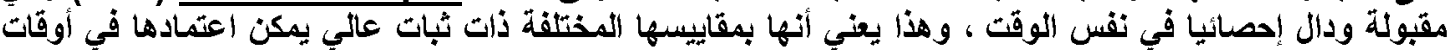

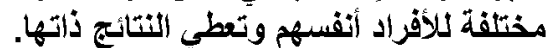

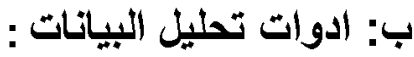

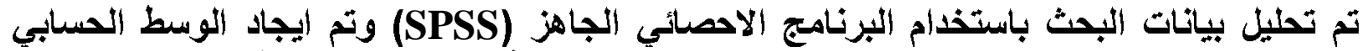

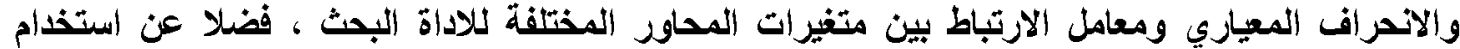

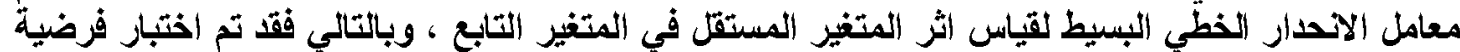

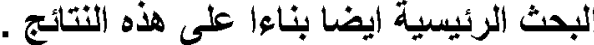

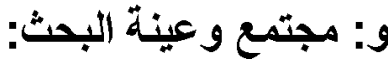

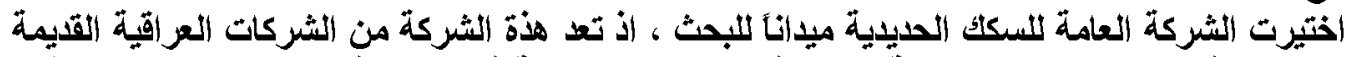

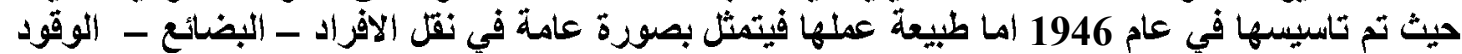

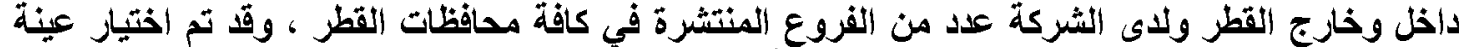

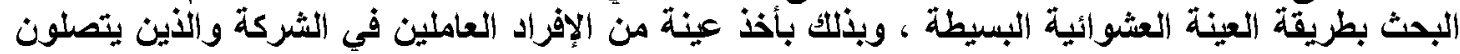

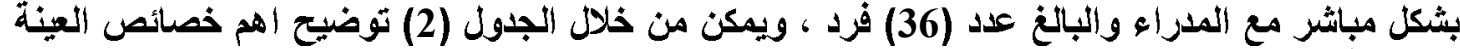

جذول (2) خصائص العينة المبحوثة

\begin{tabular}{|c|c|c|c|c|c|c|c|}
\hline \multicolumn{2}{|c|}{ سنوات الغدمة } & \multicolumn{2}{|c|}{ ألعالة الاجتماعية } & \multicolumn{2}{|c|}{ أشههادة } & \multicolumn{2}{|c|}{ الجنس } \\
\hline 7 & أقل من 5 سنوات & 13 & متزوج & 4 & ابتلائية & 20 & ذكور \\
\hline 5 & هن 6-10 سنة & \multirow{3}{*}{21} & \multirow{3}{*}{ أعزب } & 7 & متوسطة & \multirow{3}{*}{16} & \multirow{3}{*}{ إناث } \\
\hline 11 & من 11-20سنة & & & 11 & إعدادية & & \\
\hline 13 & أكثر من 20 سنة & & & 14 & بكالوريوس & & \\
\hline
\end{tabular}




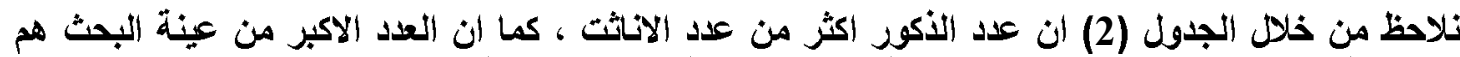

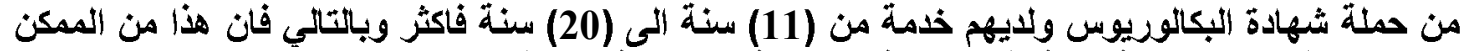

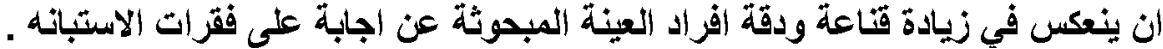
ر: المخطط الفرضي للبحث: زئن

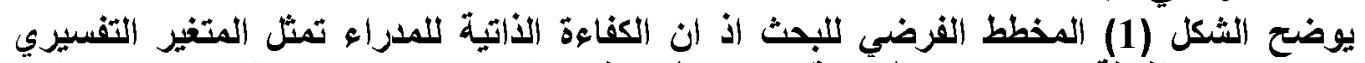

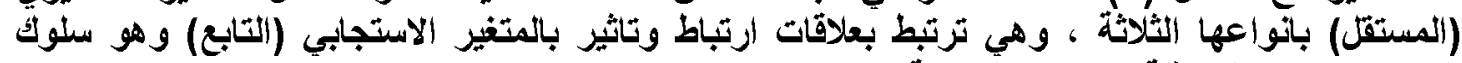

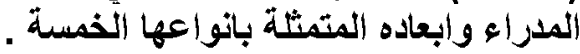

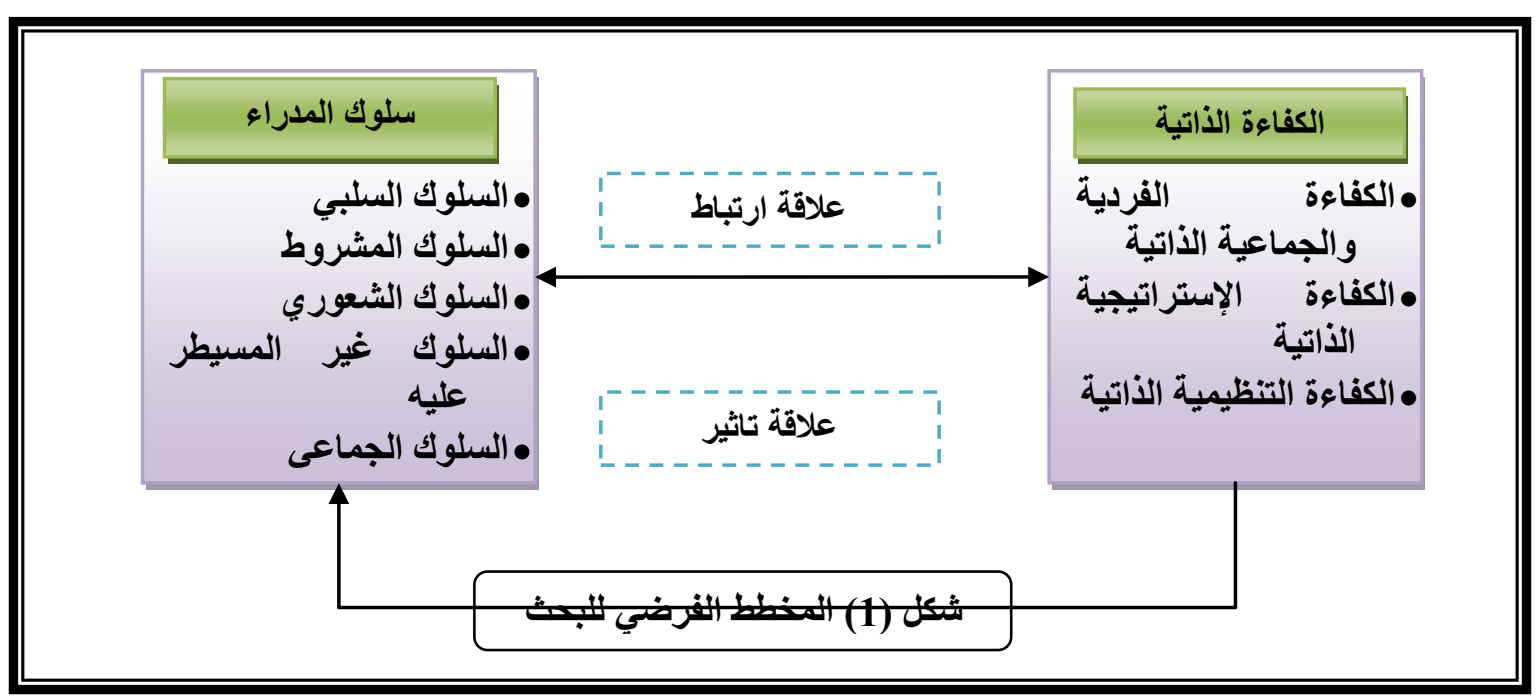

ثانيا : دراسات سابقة

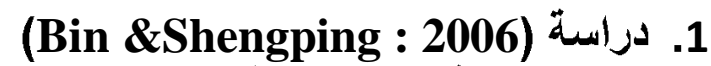

المحاكاة النوعية لاختيار واتخاذ الثرارات من قبل المدير المعتمدة على الكفاءة الأتية الادارية

Qualitative Simulation for Manager Selection Decision-Making Based on Managerial Self-Competency

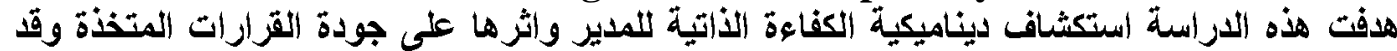

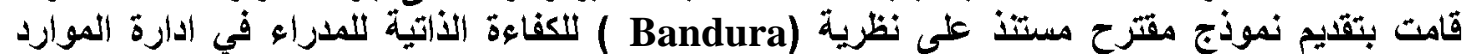

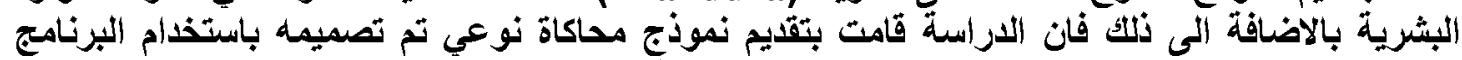

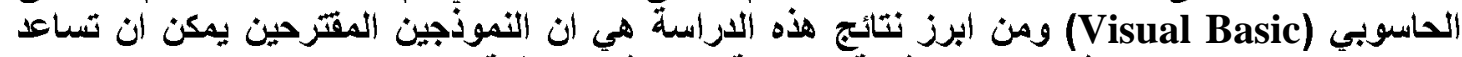

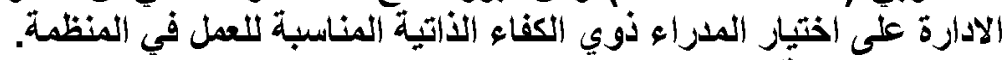
2.

تمييز وفهم مقدرات الموارد البشري ، وعلاقتها بالممارسات التظيمية

Identifying and Understanding managers Self- Competency and their Relationship to Organizational Practices

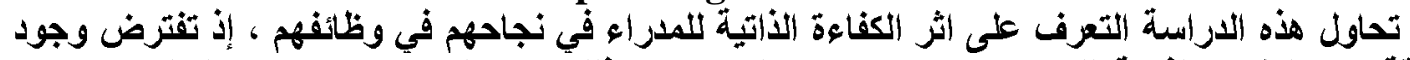

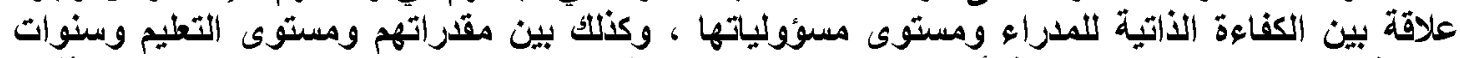

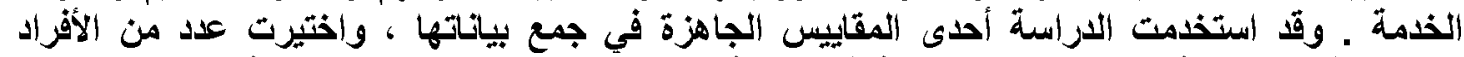

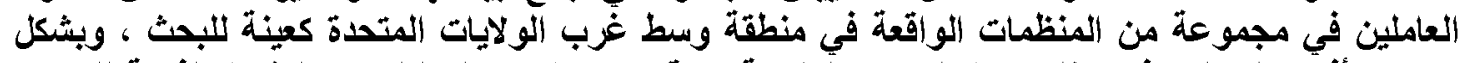

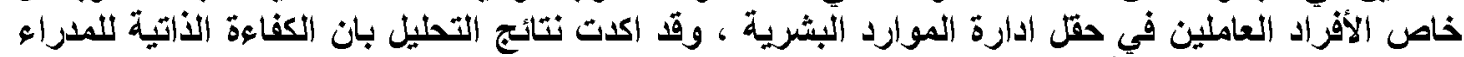

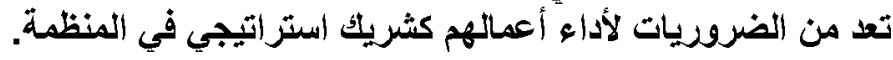




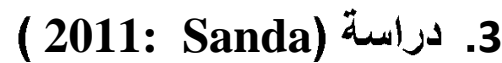

الكفاءة الأتية الادارية والسلوك الاختيار لتحسين بيئة العمل لتحقيق الاداء القوي للشركة Managerial Self- Competency and Discretionary Behavior Improving Work Environment for Small Firm Performance

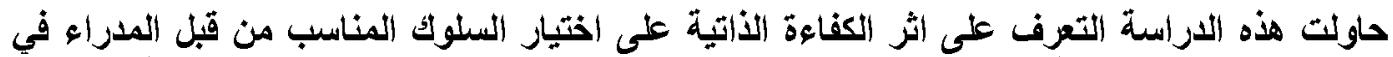

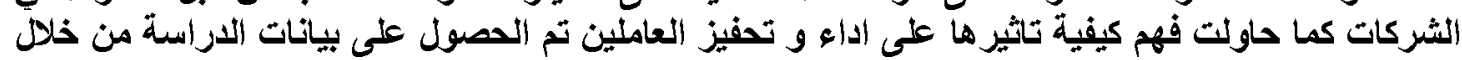

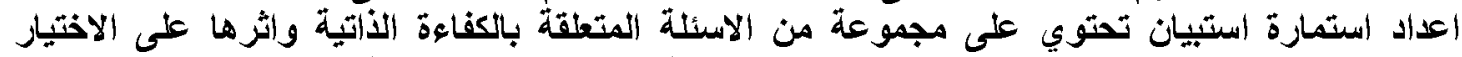

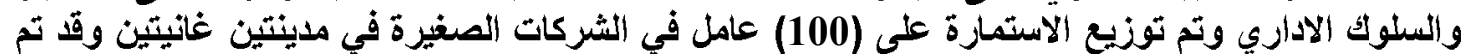

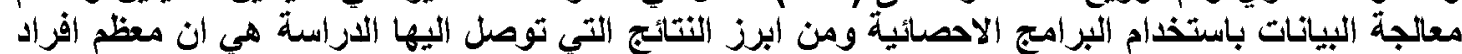

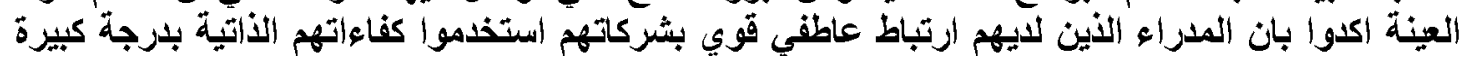

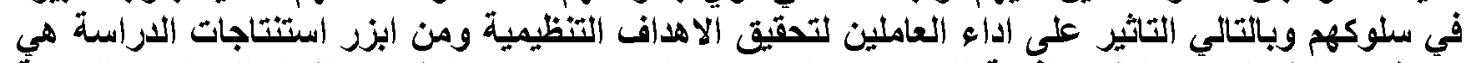

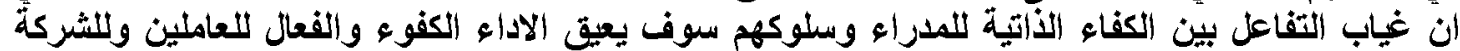

لقد شكثت الاراسات السابقة النقطة التي انطلق منها الباحثان في هذا البحث ، أذ اسهمت في تعزيز ككل.

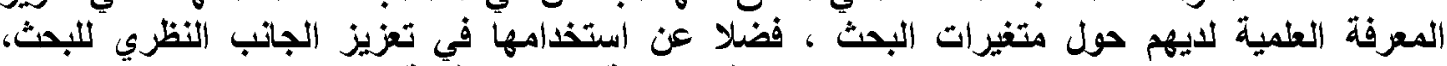

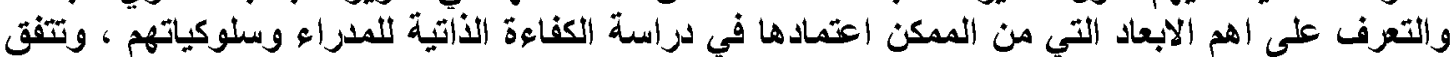

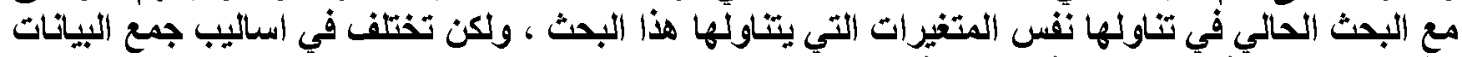

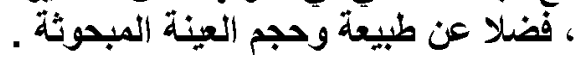

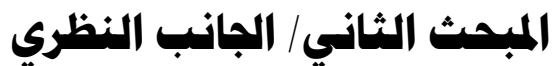

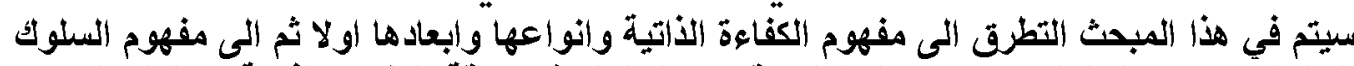

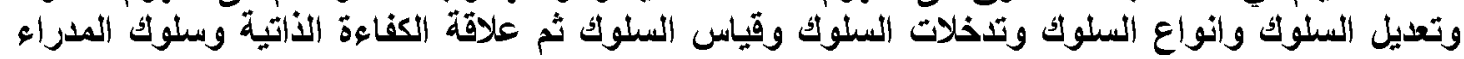

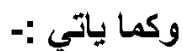

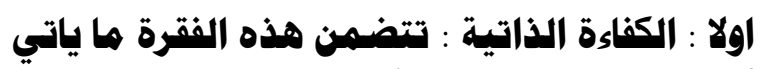

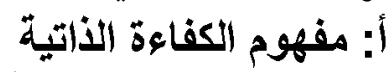

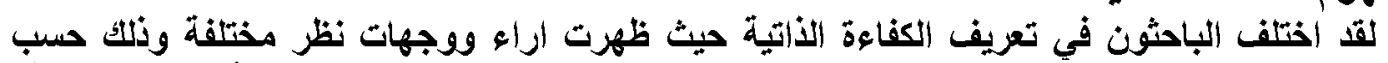

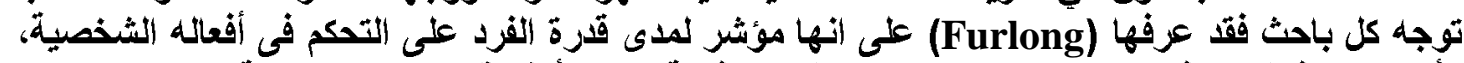

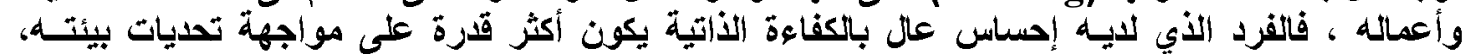

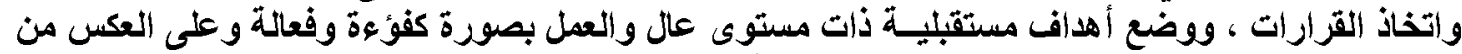

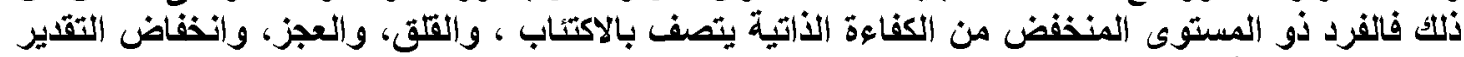

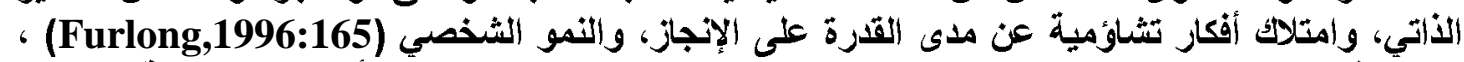

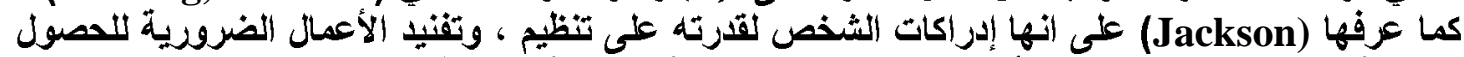

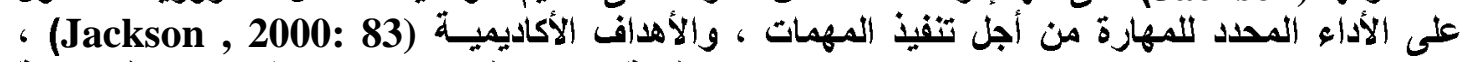

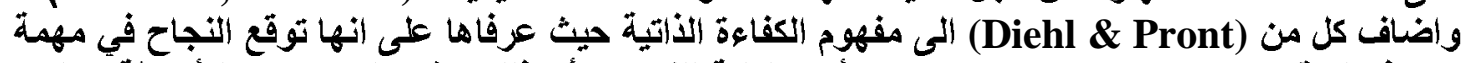

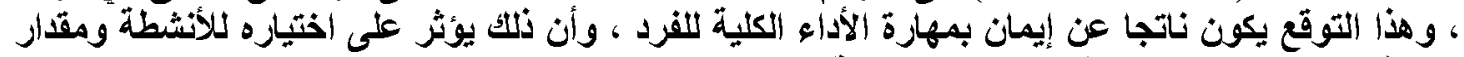

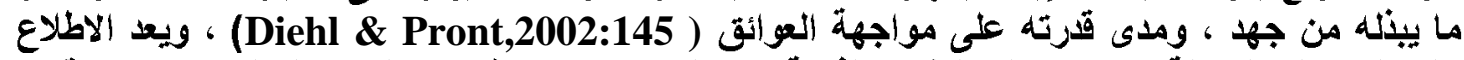

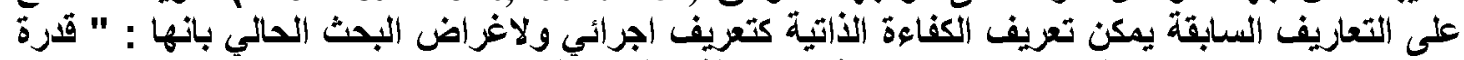

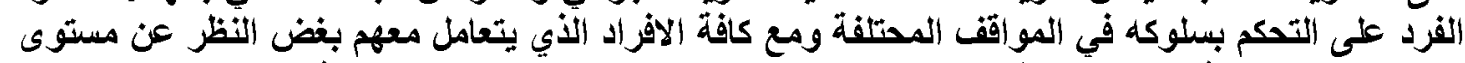

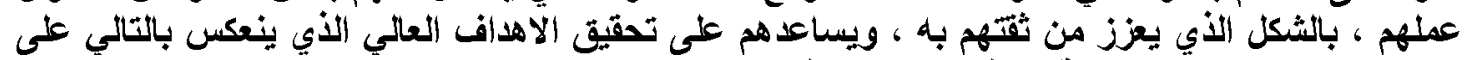

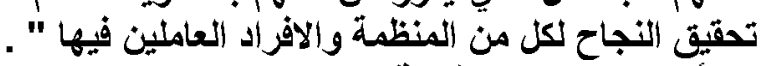

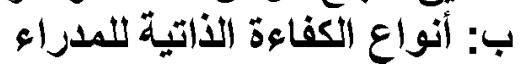

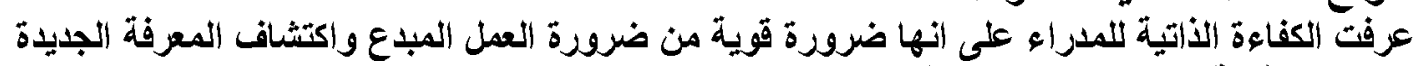

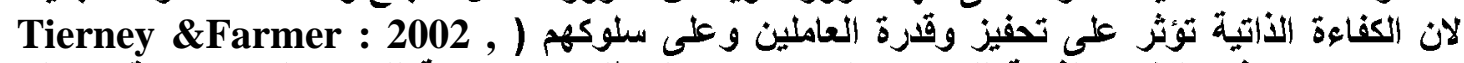

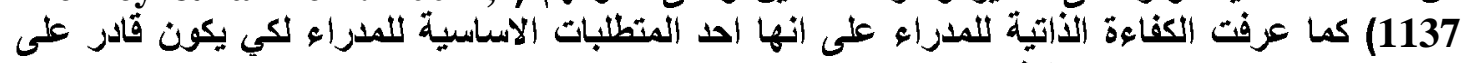

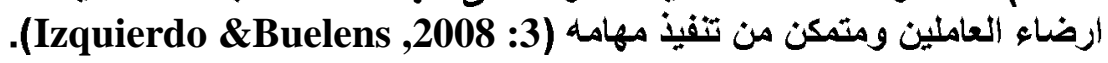




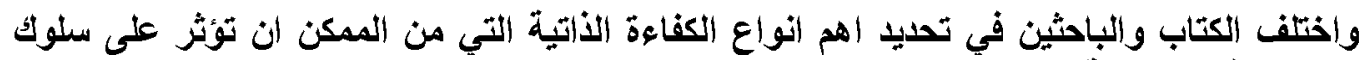

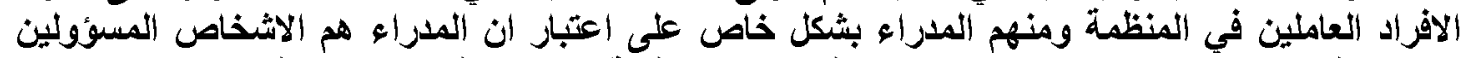

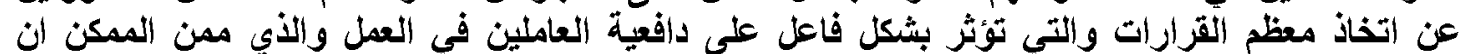

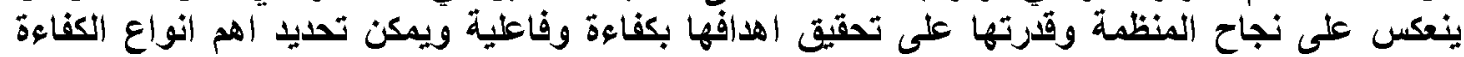

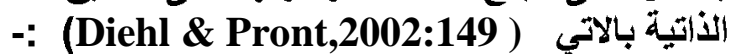

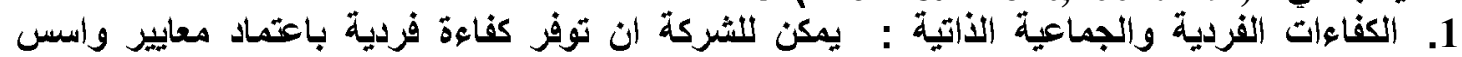

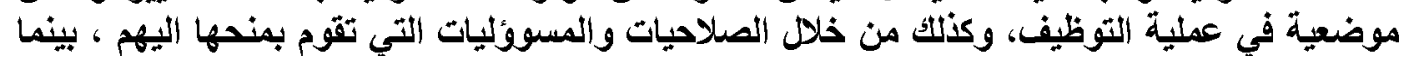

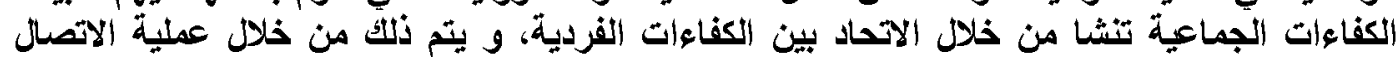

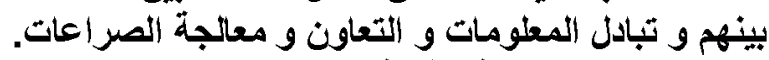

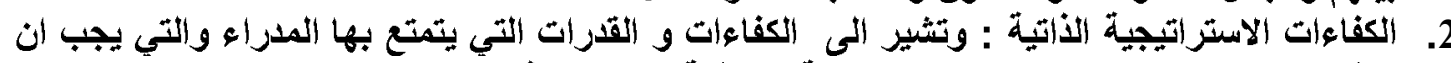

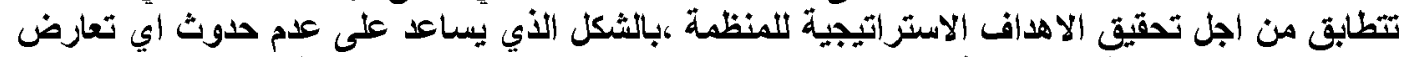

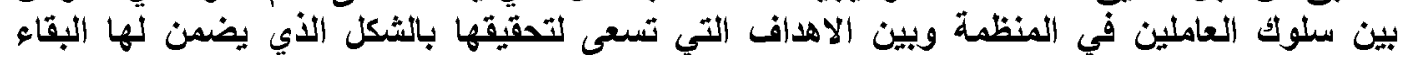
والاستمرار في العمل .

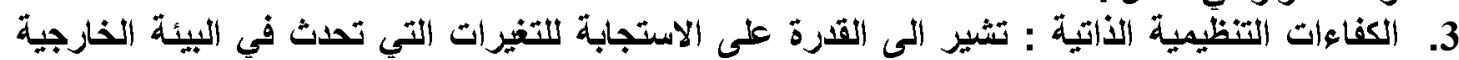

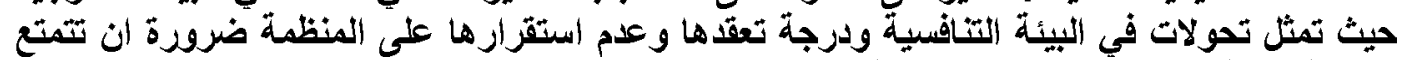

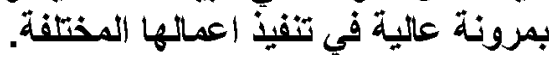
ج: أبعاد الكفاعة الأتية فئية

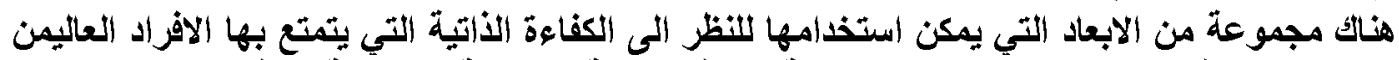

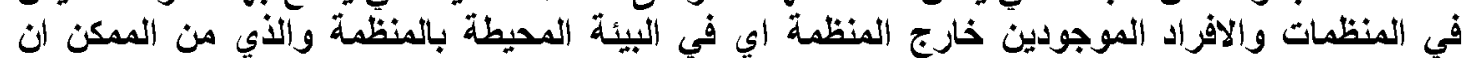

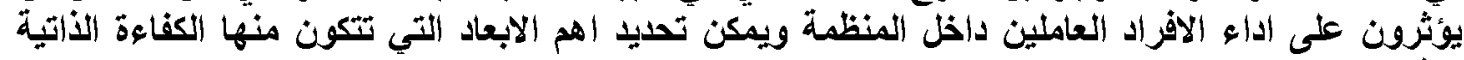
للافر اد بالاتي ( Davis, 1588 : 150 : :

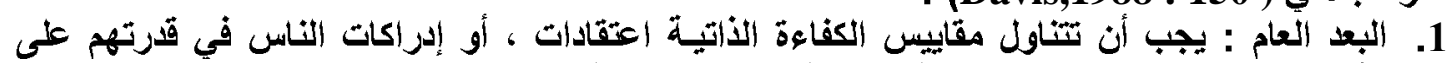

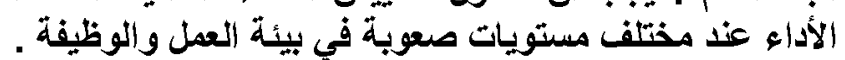

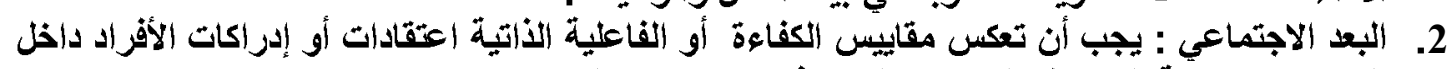

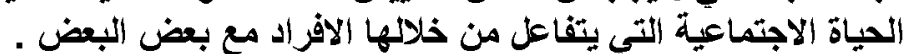

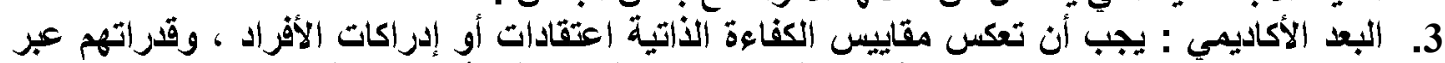

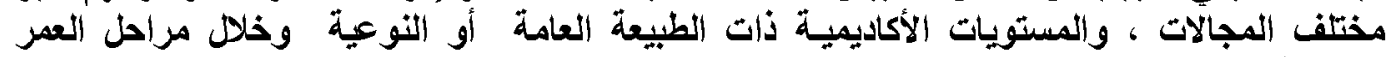

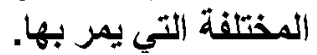

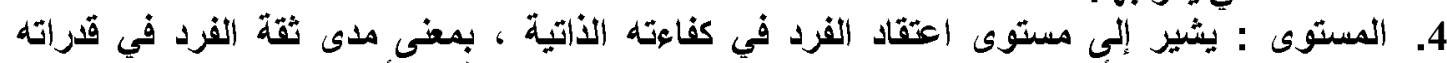

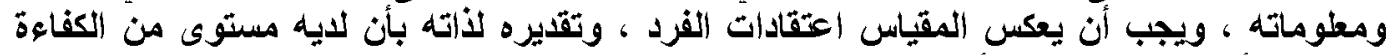

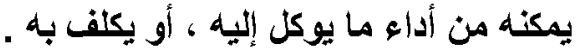

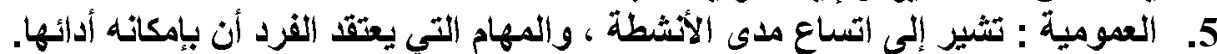

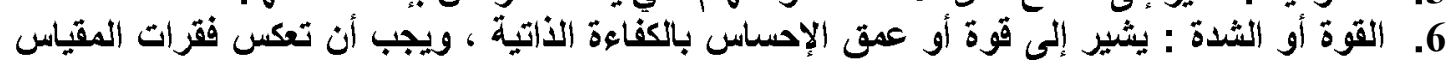

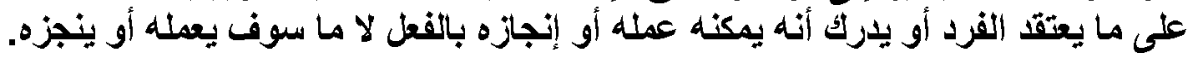

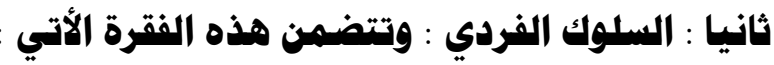

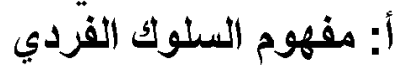

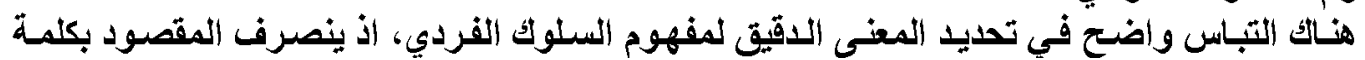

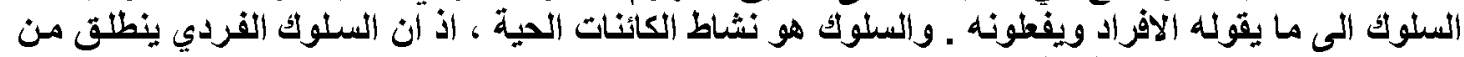

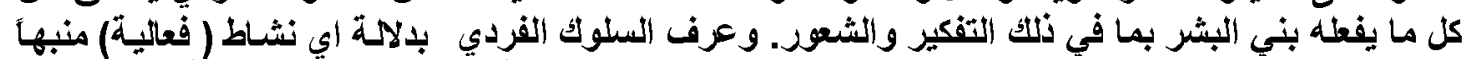

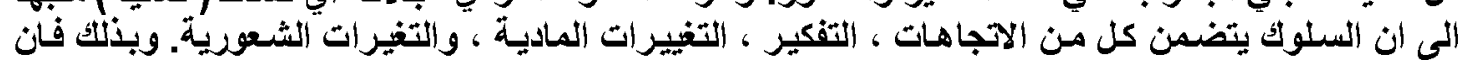

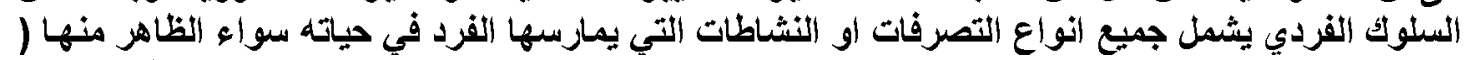

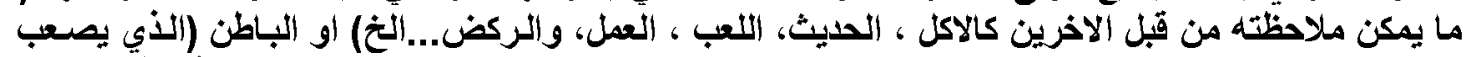

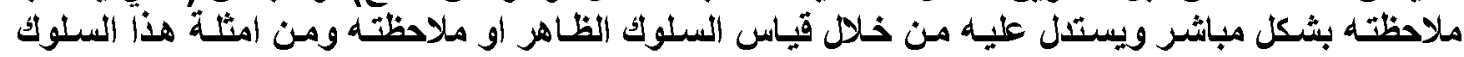

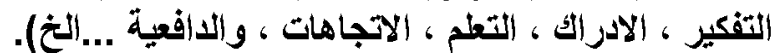




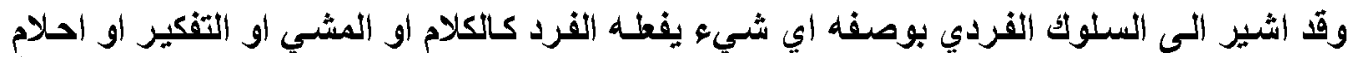

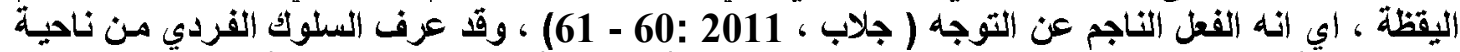

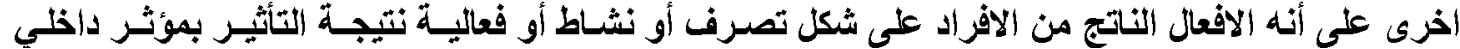

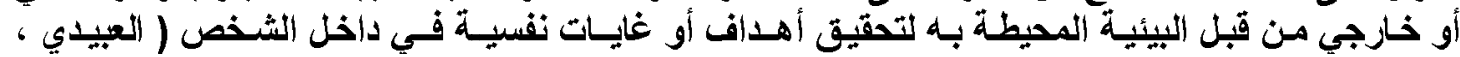

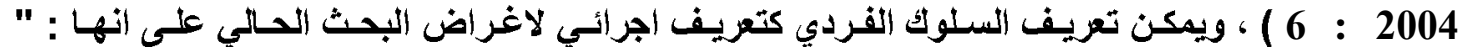

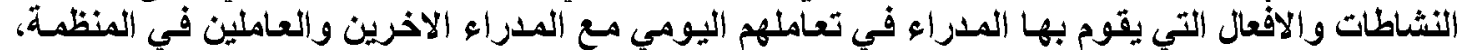

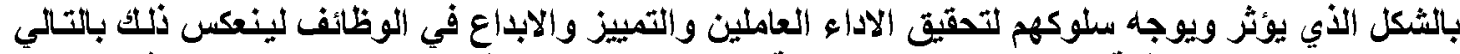

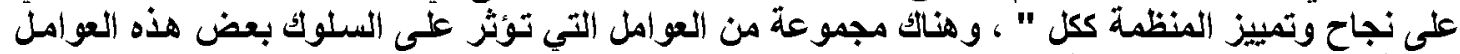

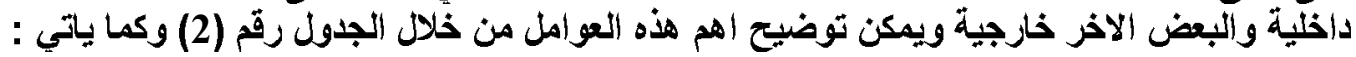

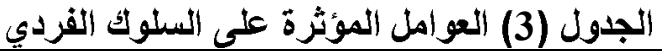

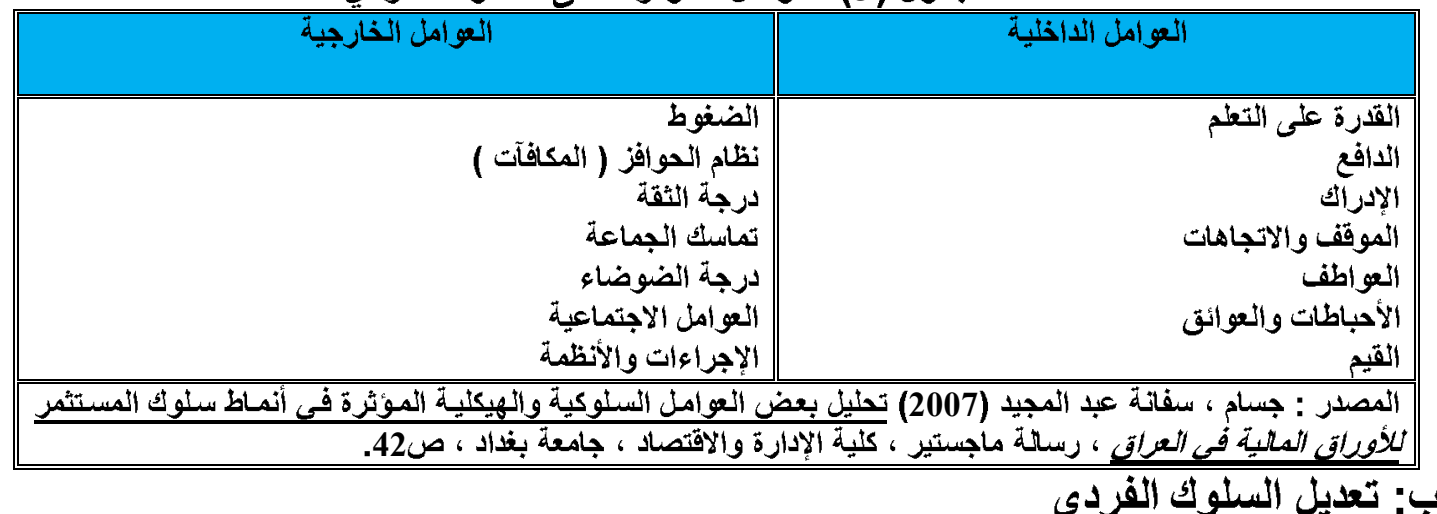

يرغب كثير من المديرين عادة بتغييز او تعديل سلوكهم وسلوك العاملين لاسباب عدة. ان عملية تغيير

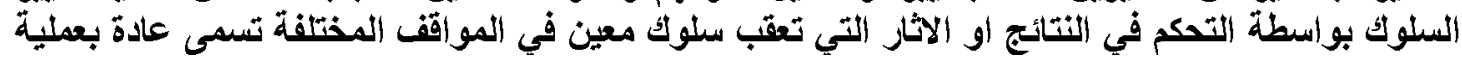

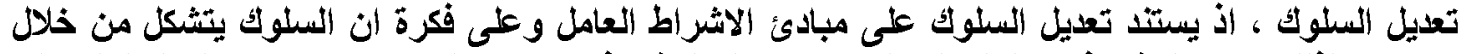

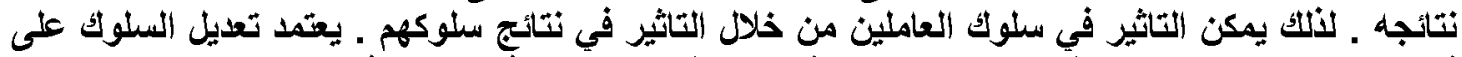

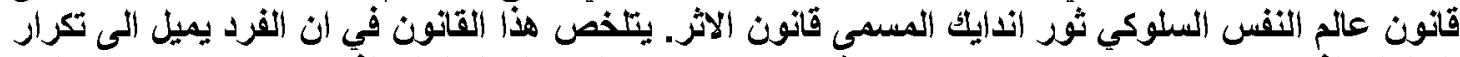

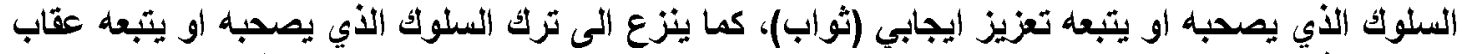

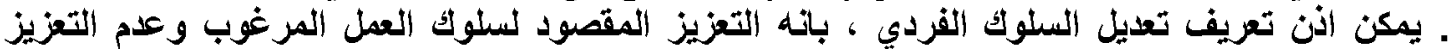

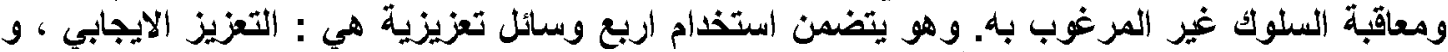

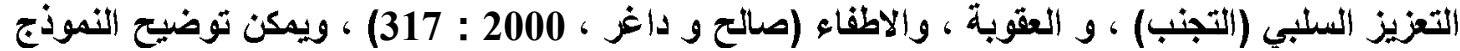
الاساسي للسوك الفردي من خلال الشكل رقم (2) :

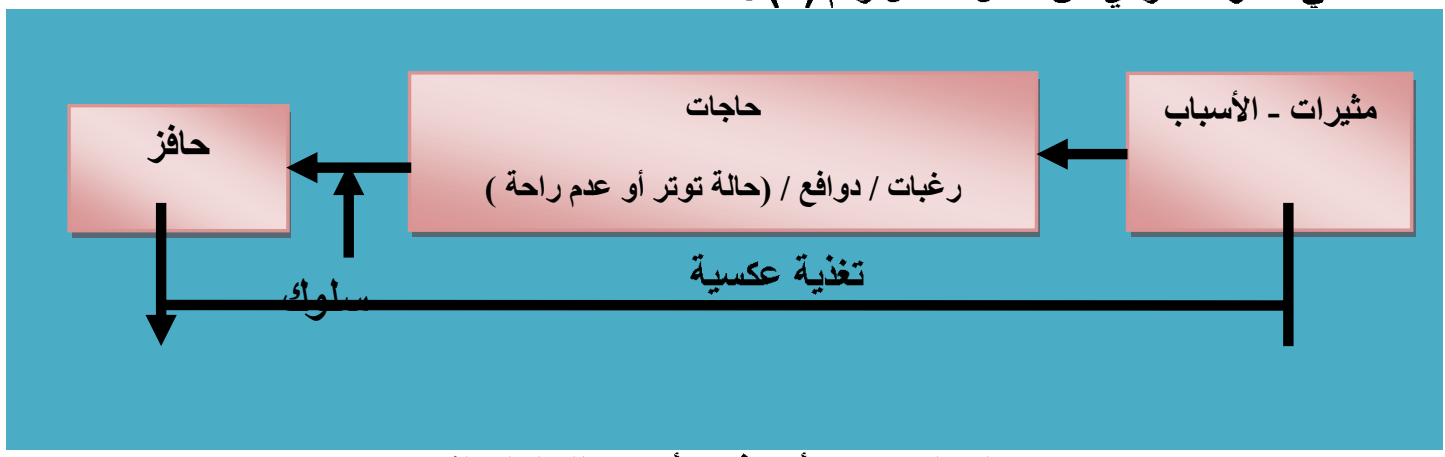

الثكل ( 2 ) الأنموذج الأساس للسلوك الثردي

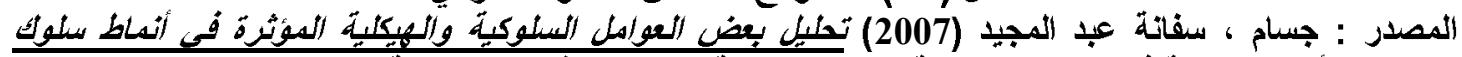

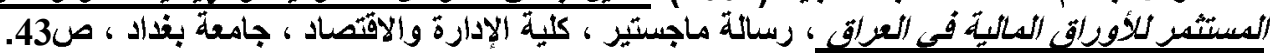


ج: اتواع السلوك الفردي وتداخلاته

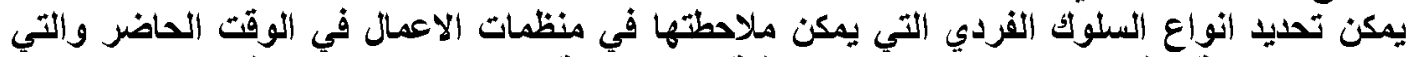

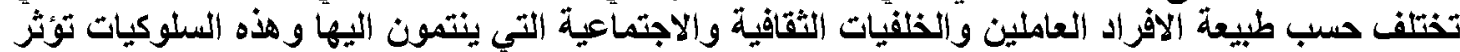

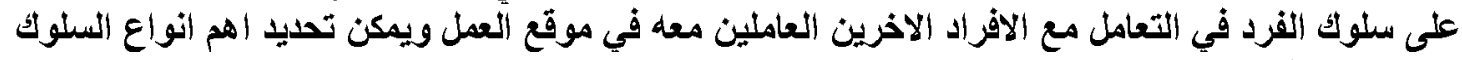

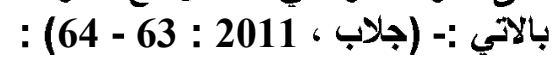

1.

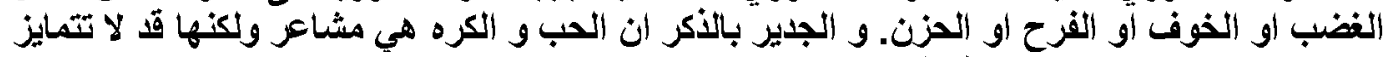

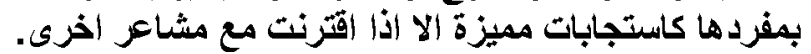

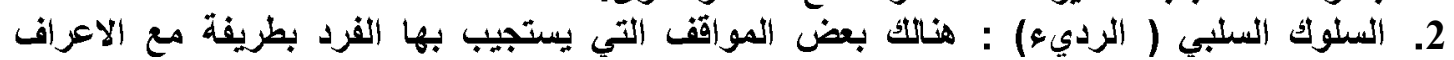

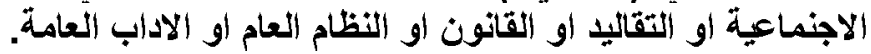

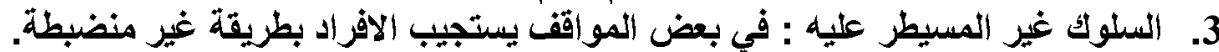

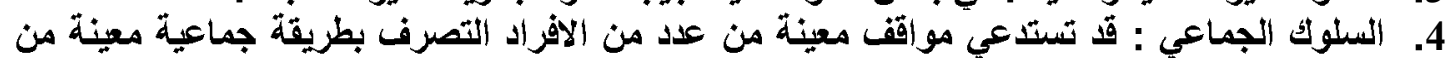
أي سبب من الاسباب. 5. السلوك المشروط : وهو السبلوك الأبي يكون دالة لنتائجه المتمثلة بالتعزيز او العقاب.

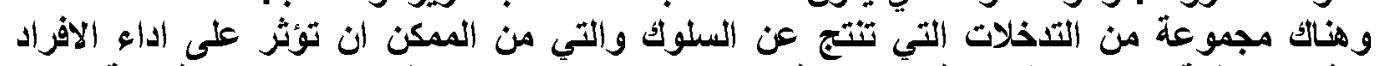

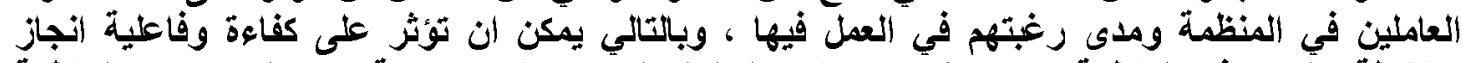

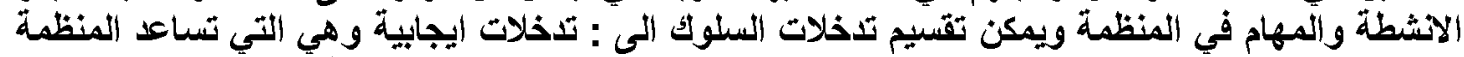

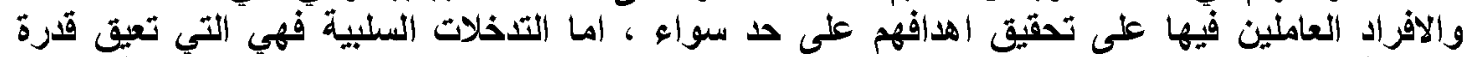

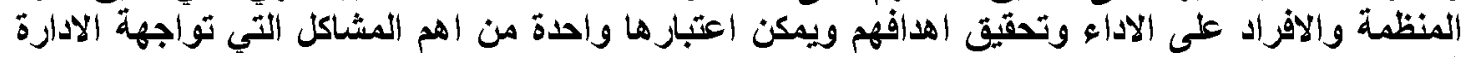

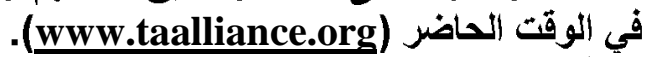
يمكن قياس السلوك الثٔي يقوم به الأفراد داخل المنظمة وبغض النظر عن نوعه على وفقى ثلاثة ابعاد

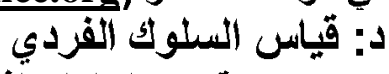
هي ( جلاب ، 2011 : 1. أمكانية أعادة التكرار : يقصد بهأ البعد تكرار حوث السلوك عبر الزمن ويقاس هذا البعد على وفق

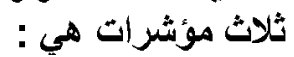

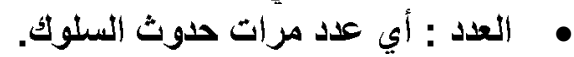

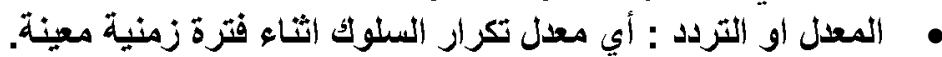

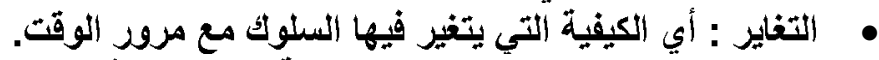

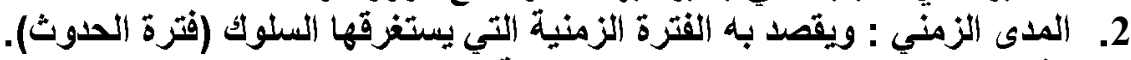

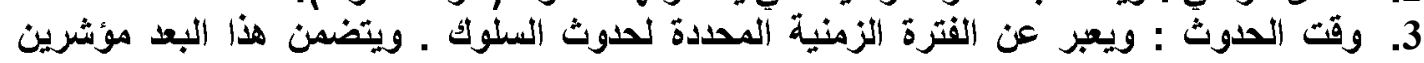
رئيسيين هما : تاخر الاستجابة : أي قياس الفترة الفاصلة بين وقت حدوث المنبه و بين الوقت التي تظهر فيه بوادر الاستجابة لهزا المنبه. • الوقت الفاصل بين الاستجابات : أي الفترة الزمنية الفاصلة بين سلوكين معينين يقعان ضمن نفس الصنف من الاستجابة . الاصل 


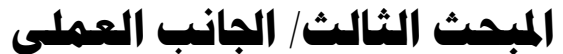

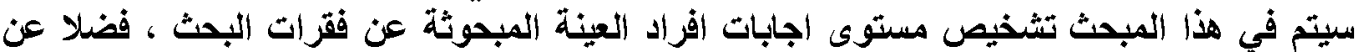

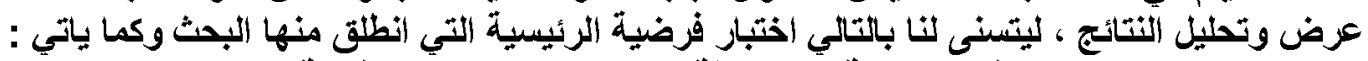

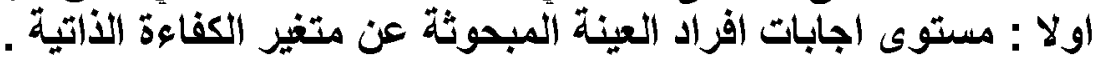

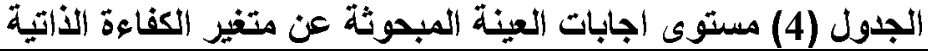

\begin{tabular}{|c|c|c|c|}
\hline 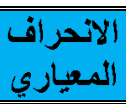 & المسابي & الاسئلة & المتفيزات \\
\hline 1.24 & 3.81 & تلمنظدة أكفاءة الأتية للمدراء على جعل العاملين بشعرون المسؤولية اتجاه & \multirow{4}{*}{ والجماعية الألكاعة } \\
\hline 0.97 & 3.75 & تساعد الكفاءة الأتية للمدراء على تصسين مستوى الأداء للعاملين ؟ & \\
\hline 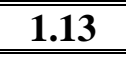 & 3.53 & تساعد الكفاءة الأتية للمدراء على تحسين ادأيهه ؟ & \\
\hline 1.11 & 3.69 & الاجمالي & \\
\hline 1.21 & 3.56 & تساعد الكفاءة الذاتية للمدراء على تعزيز الولاء التنظيمي للعاملين في المنظمة ؟ & \multirow{4}{*}{ الاستزاتيجية } \\
\hline 1.27 & 3.61 & تساعد الكفاء الأاتية للمداء على انثاء بيئة عمل مريحة للعاملين ؟ & \\
\hline 1.21 & 3.44 & تساعد الكفاعة الأتية للمدراء على حل المشاكل بين الافراد العاملين ؟ & \\
\hline 1.22 & 3.54 & الاجمالي & \\
\hline 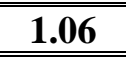 & 3.89 & تساعد الكفاءة الألية للمدراء على ترثبيا اتخاذ القرارات المههة في المنظمة ؟ & \multirow{4}{*}{ التظظيمية الكثاعة } \\
\hline 1.29 & 3.61 & تساعد الكفاءة الأتية للمدراء على تحقيق أهداف المنظمة بكفاءة وفاعلية ؟ & \\
\hline 0.99 & 3.67 & تساعد الكفاعة الأتية للمدراء على تقليص وقت انجاز العمل ؟ & \\
\hline 1.12 & 3.72 & الاجمالمي الاجم & \\
\hline 1.15 & 3.65 & & \\
\hline
\end{tabular}

1. الكفاءة الفردية والجماعية الأتية : نلاحط من خلال الجدول (4) ان الوسط الحسابي لاجمالي الكفاءة

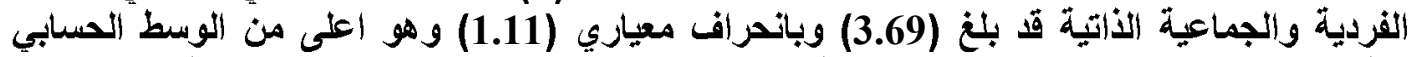

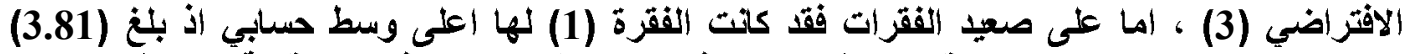

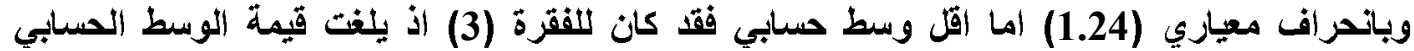

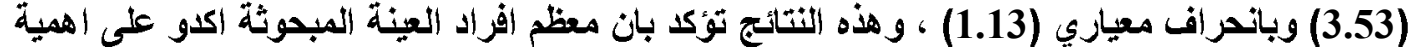

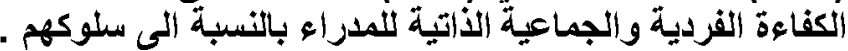

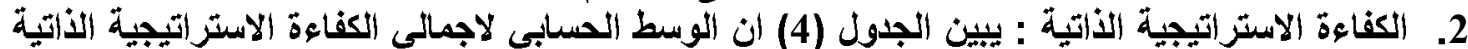

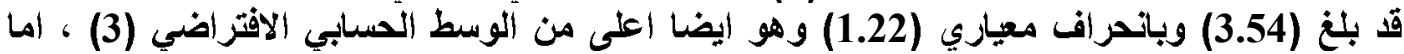

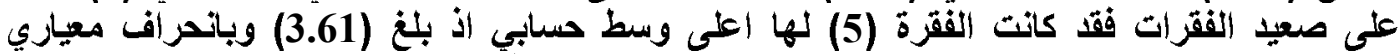

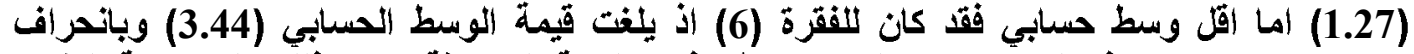

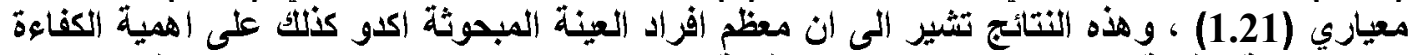

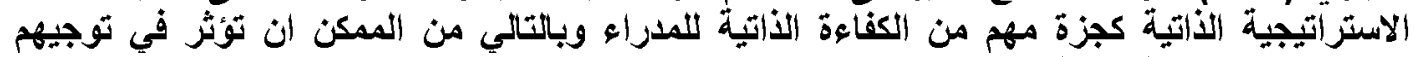

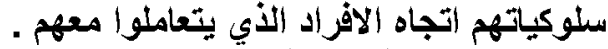

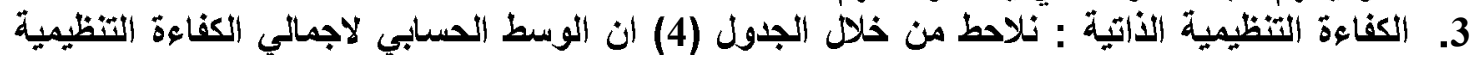

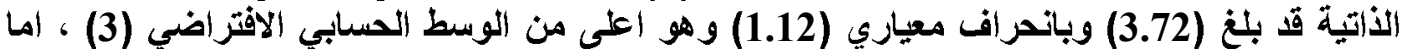

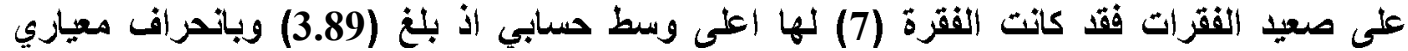

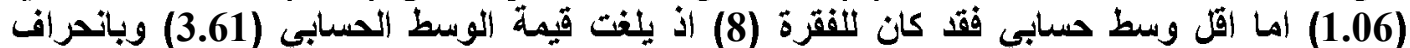

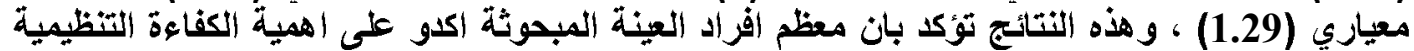

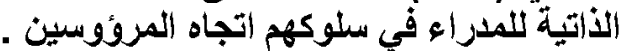

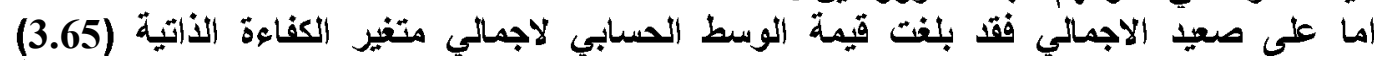

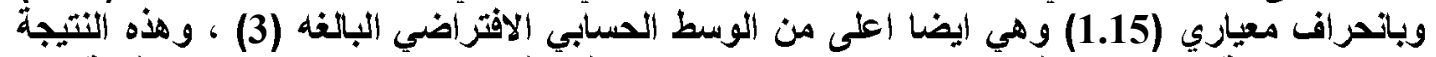

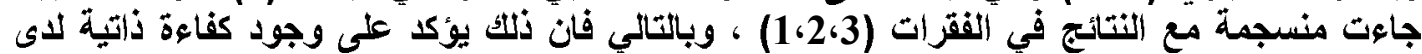

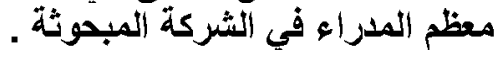




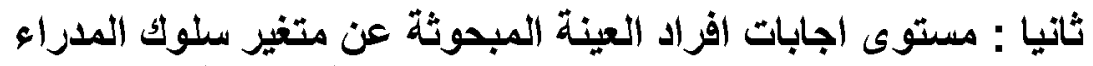

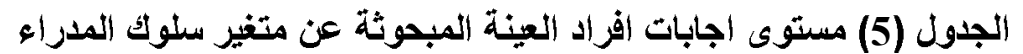

\begin{tabular}{|c|c|c|c|}
\hline 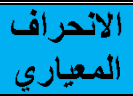 & المسابي & الاسئلة & المتغيرات \\
\hline 1.07 & 4.06 & يقوم باتخاذ القرارات بصورة مندفعة ؟ & \multirow{4}{*}{ السلبي } \\
\hline 1.23 & 2.97 & يقوم بمعاقبة العاملين وبشكل مستتر ؟ & \\
\hline$\overline{0.76}$ & 3.78 & يقوم بتحميل العاملين الخطى في العمل وبشكل مستمر . & \\
\hline 1.13 & 3.60 & الاجمالي & \\
\hline 1.45 & 3.33 & لاى المدراء مهارات عاطفية عاليه في التعامل مع العاملين؟ & \multirow{4}{*}{ 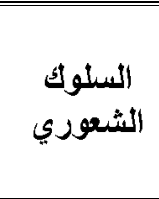 } \\
\hline 1.16 & 3.56 & لادى المدراء قابلية على الاستماع والمناقشة مع العاملين؟ & \\
\hline 1.25 & 3.42 & يقوم المدراء بمراعاة مشاعر الإفراد العاملين في المنظـة ؟ & \\
\hline 1.28 & 3.44 & الاجمالي & \\
\hline 1.15 & 3.78 & يفضل الالتزام بالقو أثين والتشريعات السائدة عثد ممارسة السلوك ؟ & \multirow{4}{*}{ المشروط } \\
\hline 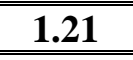 & 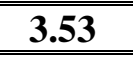 & يفضل الالتزام بالقيم والأعزاف الاجتماعية عثد ممارسة السلوك ؟ & \\
\hline 1.27 & 3.44 & يفضل التعامل مع الاخرين وفُق اسس ومبادئ رسمية ؟ & \\
\hline 1.21 & 3.58 & الاجمالي & \\
\hline 1.01 & 3.58 & لا يتعامل المدراء بحكمة مع المواقف الحرجة ؟ & \multirow{4}{*}{ المسيطز غيز } \\
\hline 0.86 & 3.69 & لا يسيطر على موقةة في حالة حذوث مشاكل مفاجأة ؟ & \\
\hline 1.00 & 3.50 & لا يقوم باستغلال القزص الجديدة وبشكل جيد ؟ & \\
\hline 0.95 & 3.59 & الاجماليى الاجي & \\
\hline 0.91 & $\overline{3.72}$ & يشجع المدراء العمل الجماعي ويقوموا بتوفيز الاعم لجماعات العمل ؟ & \multirow{4}{*}{ الجماعي } \\
\hline 1.06 & 4.03 & يتمتع بروح الفزيق العالية ؟ & \\
\hline 0.98 & 3.81 & يقوم بتَريب الإفراد العاملين معه على كيفية العمل كمجوعة متكاملة & \\
\hline 0.98 & 3.85 & الاجمالي & \\
\hline 1.11 & 3.61 & الاجمالي & \\
\hline
\end{tabular}

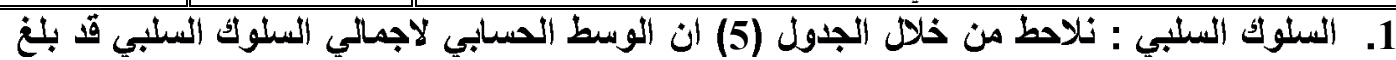

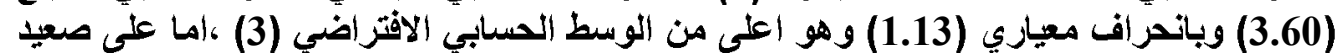

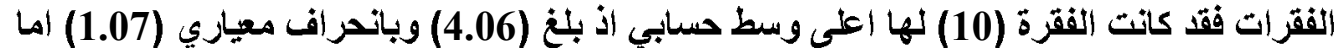

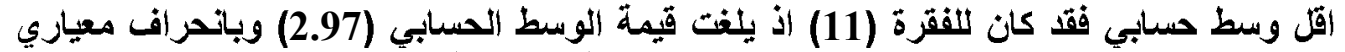

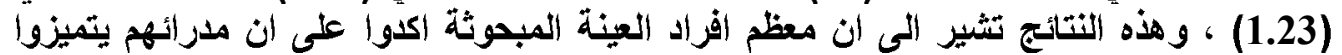

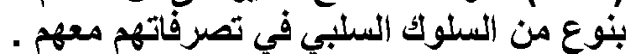

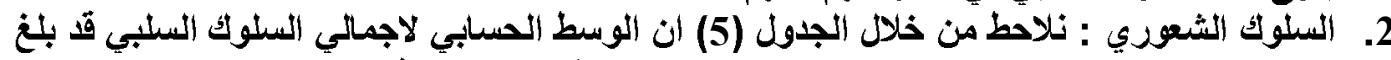

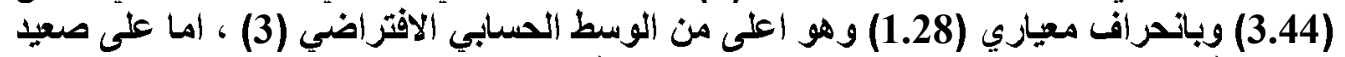

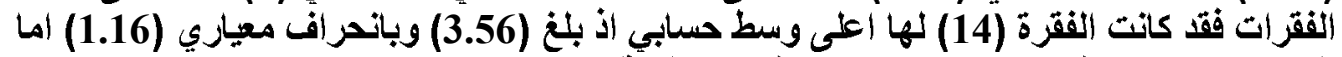

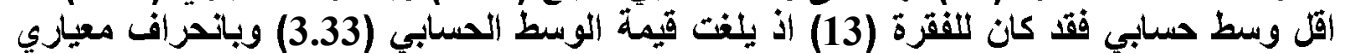

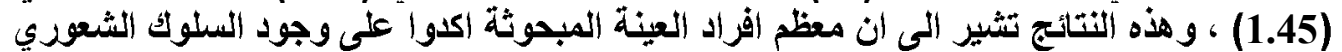

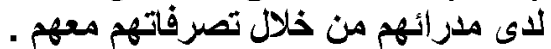
3. السلوك المشروط : يبين الجدول (5) ان الوسط الحسابي لاجمالي السلوك المشروط قد بلغ (3.58)

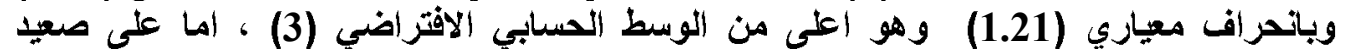

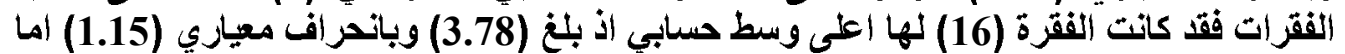

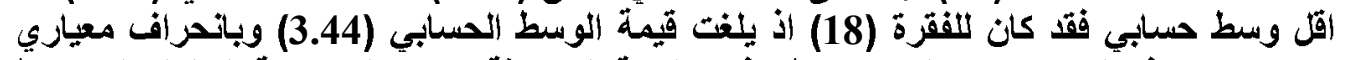

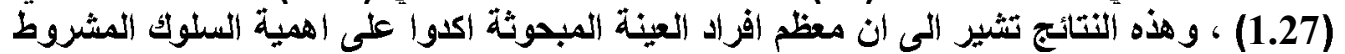

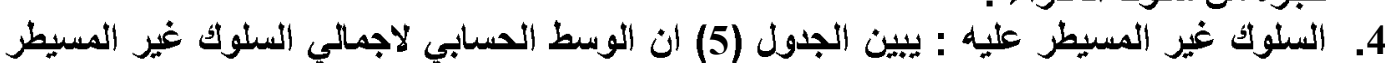

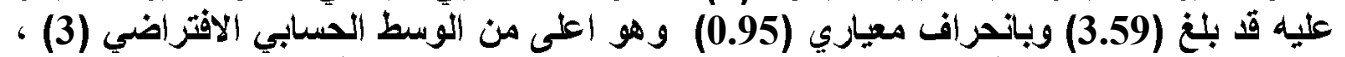

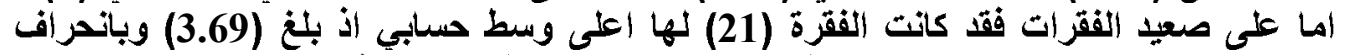

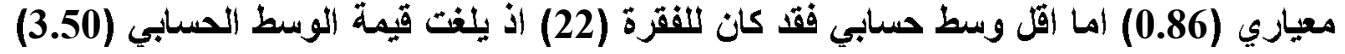


وياتحراف معياري (1.01) ، وهذه النتائج تثير الى ان معظم افراد العينة المبحوثة اكدوا على ان

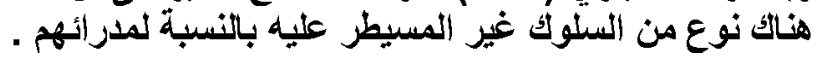

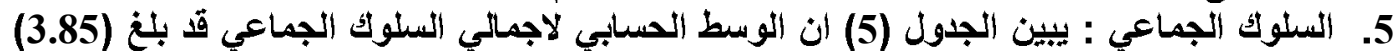

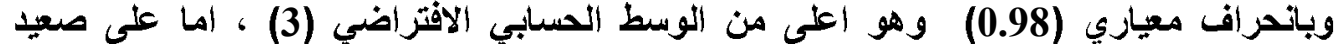

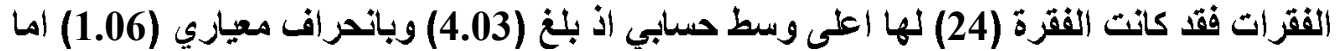

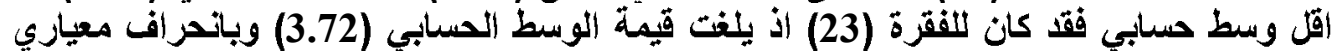

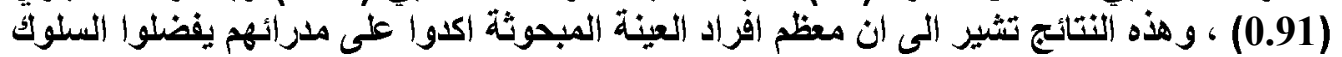

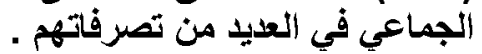

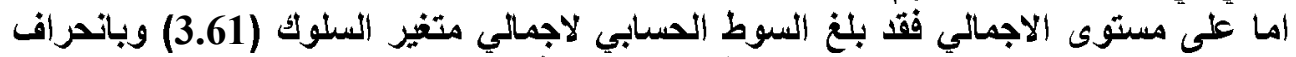

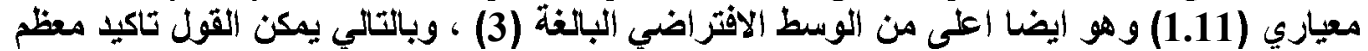

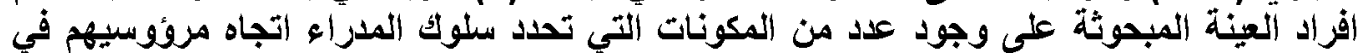

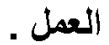

ثالثا : علاقة الارتباط بين الابعاد الفرعية للكفاعة الأتية

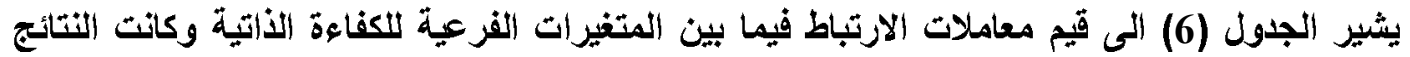

جدول(6) الارتباطات بين ابعاد الكفاءة الذاتية

\begin{tabular}{|c|c|c|c|c|}
\hline الكفاعة التبظيمبة & الكفاءة الاستئزاتيجية & والجماعية الأنتية & & $ت$ \\
\hline $0.689 * *$ & $0.620 * *$ & - & الكفاعة الفردية والجماعية الذاتية & 1 \\
\hline $0.638 * *$ & - & - & الكفاءة الاستر اتيجية الذاتية & 2 \\
\hline - & - & - & الكفاعة التتظيمية الذاتبة & 3 \\
\hline
\end{tabular}

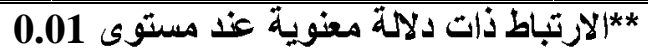

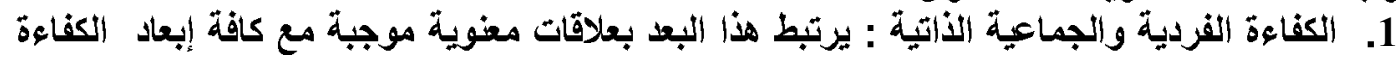

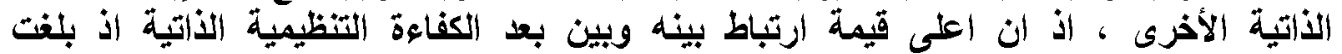
(0.01) واقل معامل ارتباط بينه وبين بعد (الكفاءة الاستراتيجية

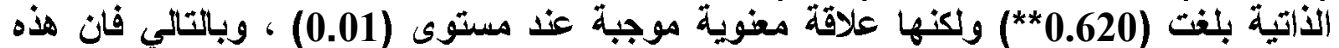

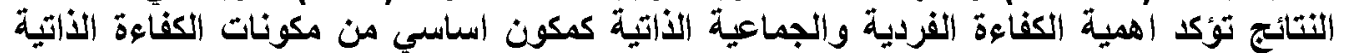

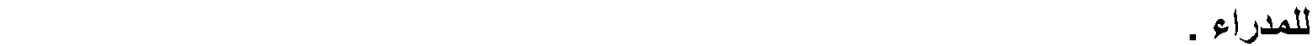
2. الكفاءة الستراتيجية الأتية : كاتت جميع العلاقات بين هذات البعد وجميع الإبعاد الأخرى معنوية

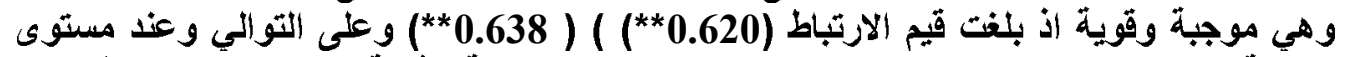

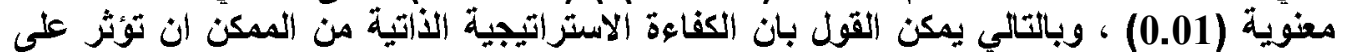

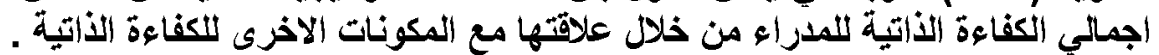

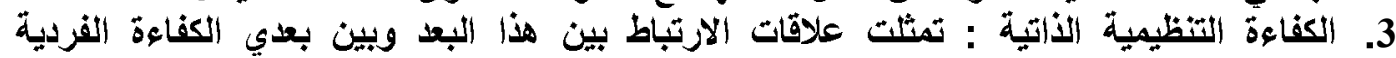

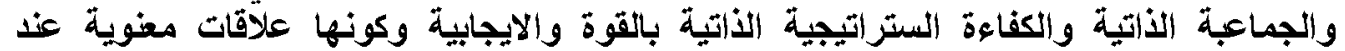

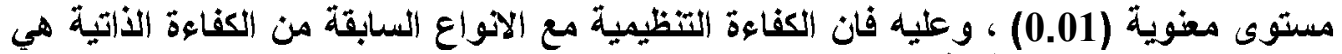

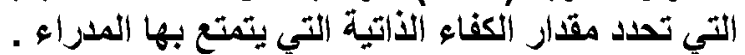




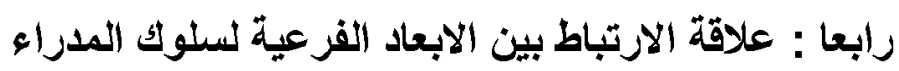

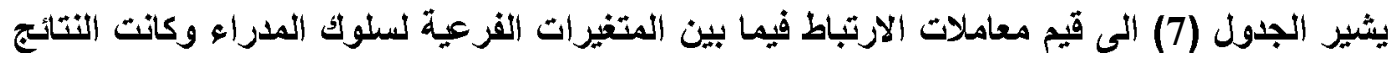

جدول(7) الارتباطات البينية بين ابعاد سلوك المدراء

\begin{tabular}{|c|c|c|c|c|c|c|}
\hline الجماعي & المسيطر غليز & المشروط & الشعوري & السلبوك & & $ت$ \\
\hline 0.292 & $0.363^{*}$ & $\mathbf{0 . 1 1 7}$ & 0.262 & - & السلوك السلبي & 1 \\
\hline 0.128 & $0.356 *$ & 0.395* & - & - & ألسلوك الشعوري & 2 \\
\hline$*^{*} 0.245$ & $0.485 * *$ & - & - & - & اللسلو المشروط & 3 \\
\hline $0.410 * *$ & - & - & - & - & السلوك غيز المسيطز & 4 \\
\hline - & - & - & - & - & السلوك الجماعي & 5 \\
\hline
\end{tabular}

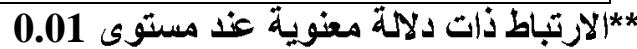

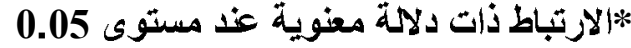

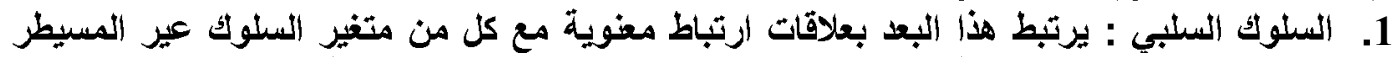

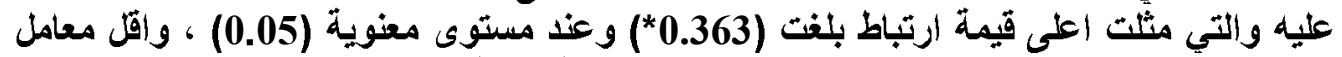

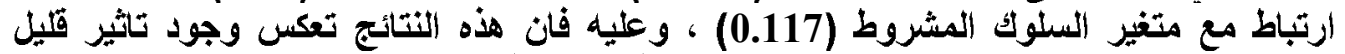

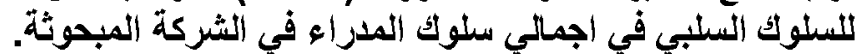

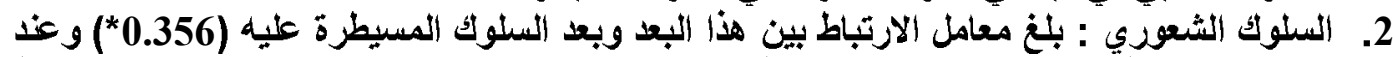

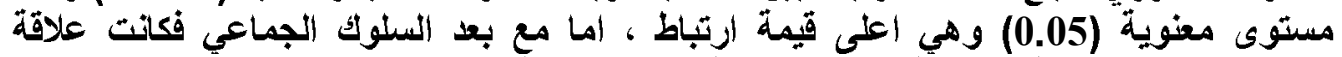

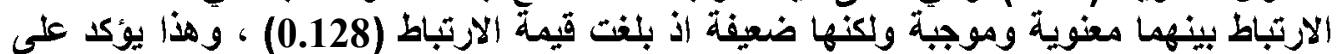

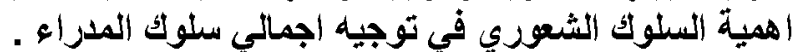

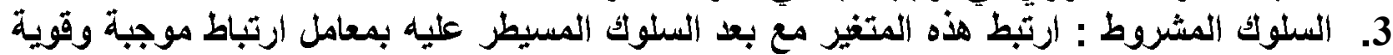
اذذ بلغت قيمته (0.485*

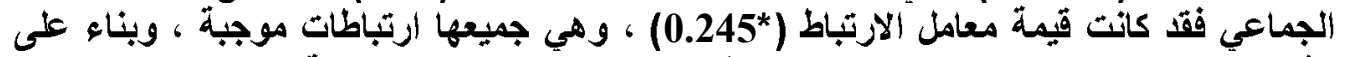

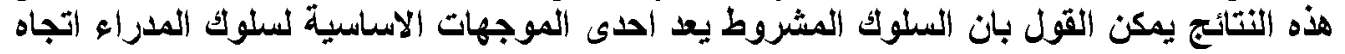

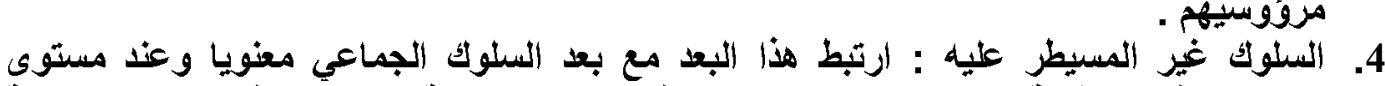

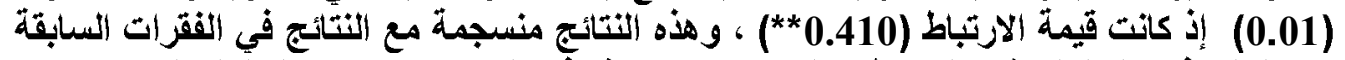

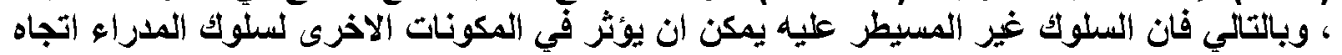

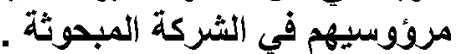
وتثبير نتائج الارتباط الموضحة فئة في الجنول (5) والجدول(6) الفى تجانس فيما بين الإبعاد

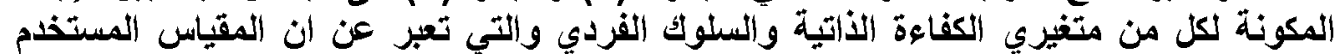

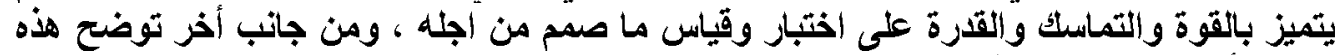

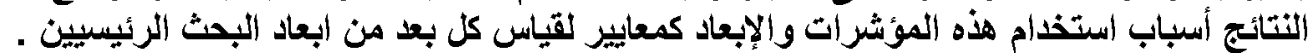


خامسا : تحليل علاقة الارتباط بين الكفاعة الأتية وسلوك المدراء

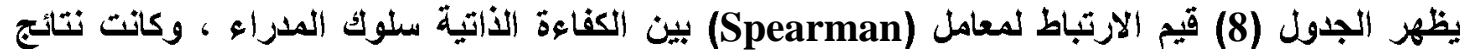

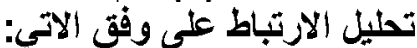

جدول(8) قيم الارتباط لمعامل (spearman) بين الكفاءة الأتية سلولك المدراء

\begin{tabular}{|c|c|c|c|c|c|c|}
\hline الاجمائي & السنوك الجماعي & المسيطر عليه & المشروط & الشعوري & السلوك السلبي & \\
\hline $0.366^{*}$ & $0.620 * *$ & 0.271 & 0.399* & 0.258 & 0.314 & الألتية ألفية الفردية و والجماعية \\
\hline 0.338* & $0.689 * *$ & $0.347 *$ & 0.160 & ${ }^{*} 0.305$ & $0.471 * *$ & الكفاءة الاستراتيجية الذاتية \\
\hline 0.507** & $0.643 * *$ & 0.457** & 0.582* & 0.349* & $0.467 * *$ & الكفاءة التنظيمية الأاتية \\
\hline$\overline{\mathbf{0 . 4 3 8} * *}$ & 0.553** & $\overline{0.383 *}$ & $\begin{array}{l}0.210 \\
\end{array}$ & (0.336* & $0.474 * *$ & الاجمالي \\
\hline
\end{tabular}

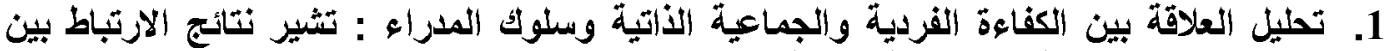

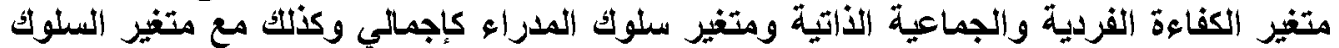

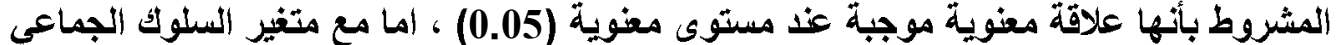

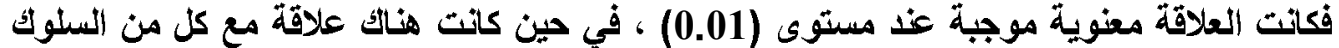

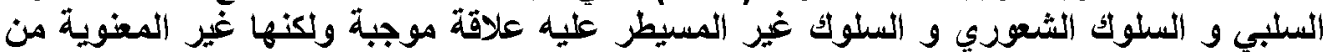

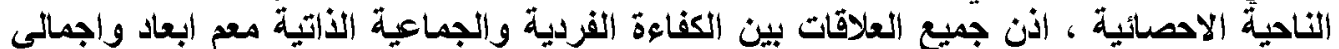

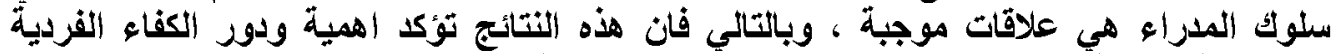

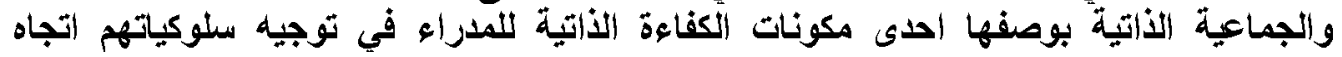
2. تحليل العلاقة بين الكفاعة الاستراتيجية الأتية وسلوك المدراء : تثيلير نتأتج الارتباط بين متغير

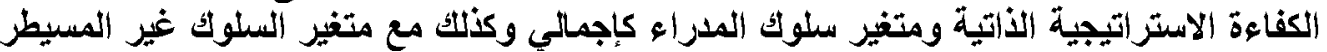

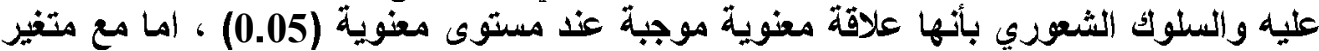

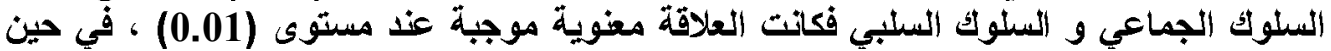

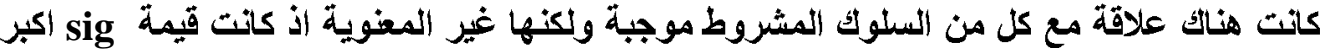

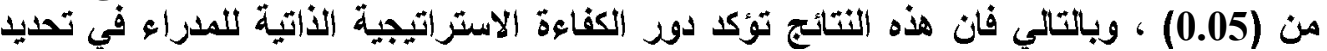
طبيعة سلوكياتهم في المواقف المختفة التي من الممكن ان تواجهم في عملياتهم اليومية مع التئية

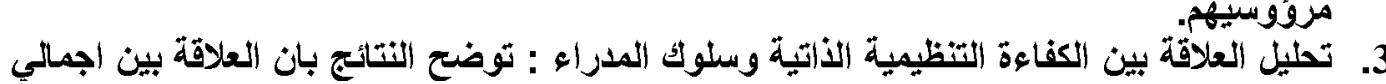

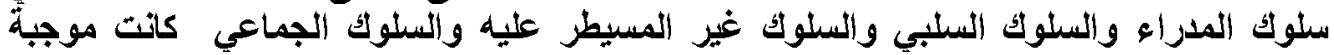

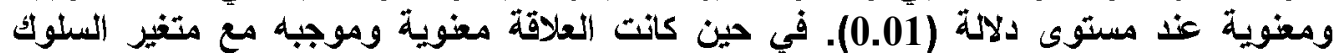

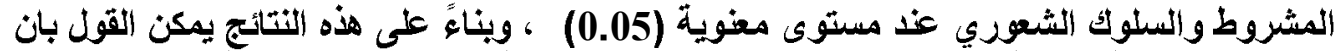
الكفاءة التظيمية الذاتية للمدراء تعد من المحركات الاساسية للسلوكيات المختلفة التى يقوم بهاء

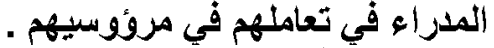

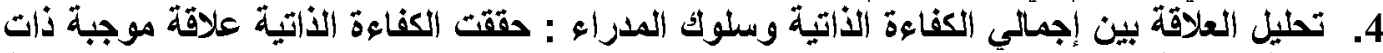

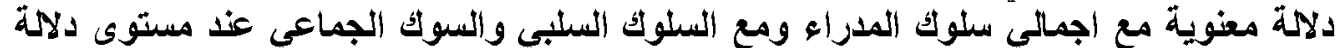

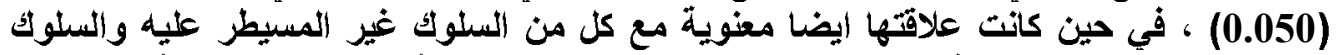

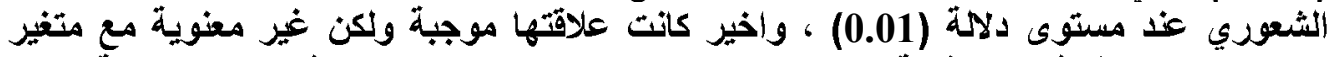

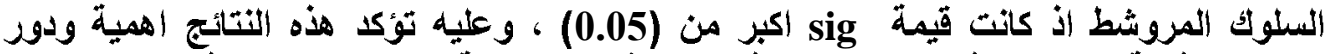

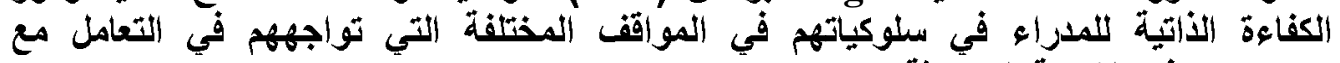




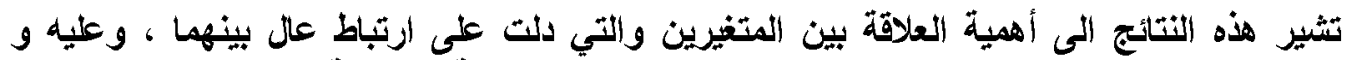

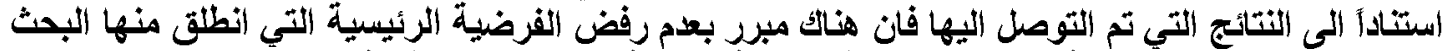
و التي تنص على وجود علاقة ارتباط وتاثير ذات دلانة معنوية بين الكفاءة الذاتية للدديرين وسلوكهم اتجاه

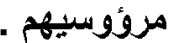

سادسا : تحليل اثر الكفاعة الأتية في سلوك المداءراء

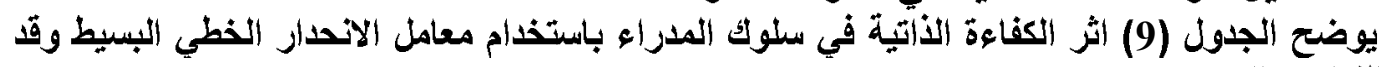
كانت النتائج كالاتي :-

جدول (9) نتائج تاثير الكفاءة الأتية في سلوك المدراء

\begin{tabular}{|c|c|c|c|c|c|}
\hline 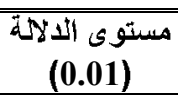 & المحسوبة & التحديد معامل & $\begin{array}{l}\text { قيمة معامل بيتا } \\
\text { (B) }\end{array}$ & قيمة الثابتة & ألمتغيرات المستقةد \\
\hline يوجد تاثير & 5.267 & 0.650 & 0.738 & 0.643 & الكانتاعة الفردية والجماعية \\
\hline يوجد تاثير & 3.854 & 0.519 & 0.450 & 0.619 & الكفاعة الاستراتيجية الذاتية \\
\hline يوجد تاثير & 11.155 & 0.497 & 0.476 & 0.303 & الكفاءة التنظيمية الأتاتية \\
\hline يوجد تاثير & 6.464 & 0.47 & 0.546 & 0.476 & الكفاءة الألتية \\
\hline
\end{tabular}

وفيما ياتي توضيح العلاقة لقيم معامل الاتحدار :-

ل V

ح V

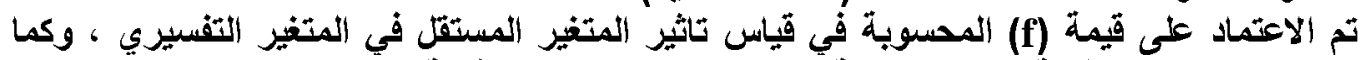

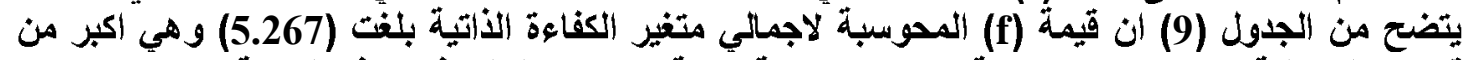

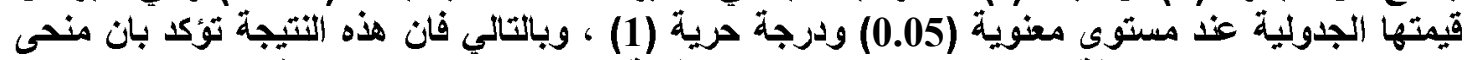

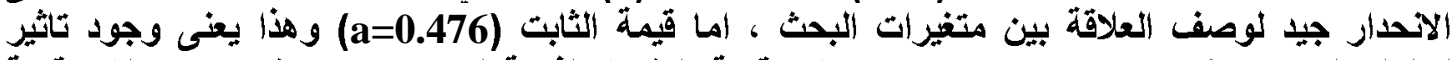

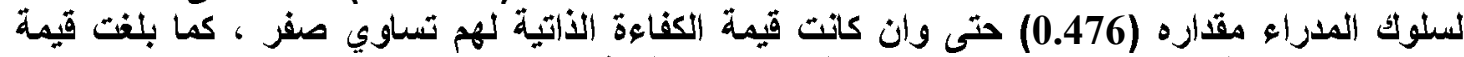

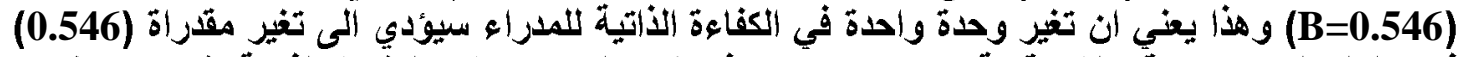

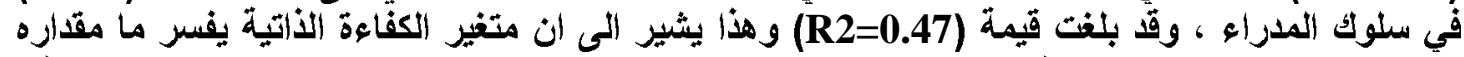

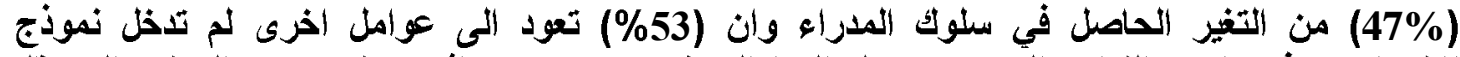

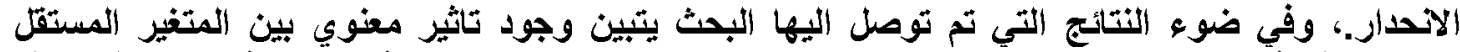

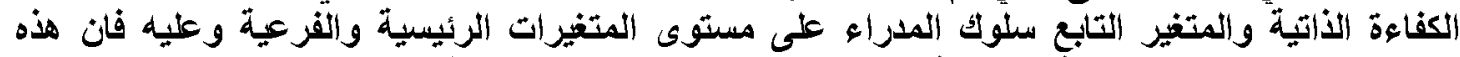

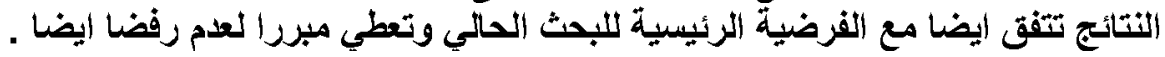




\section{المبحث الرابع/ الاستنتاجات والتوصيات}

أولا : الاستنتاجات

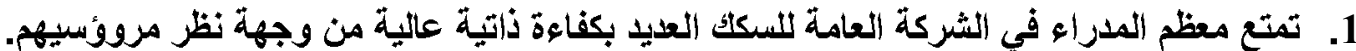

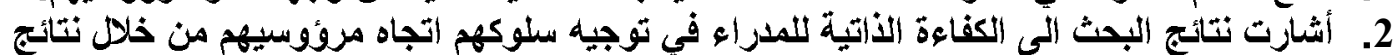

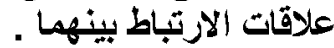
3. هناك إسهام ودور مؤثر للكفاءة الذاتية في تعزيز وتوجيه سلوك المدراء وقرته على التأثير في 4. الآخرين. تباين مستويات الكفاءة الأتية التي يتمتع بها المدراء من منظمة إلى أخرى وحتى داخل المنظمة الواحث وبين مستوياتها المختلفة .

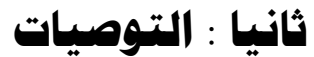

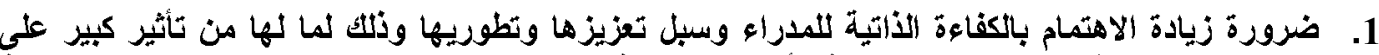

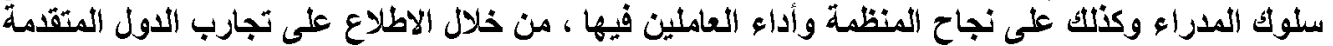

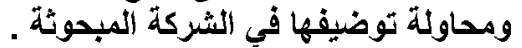

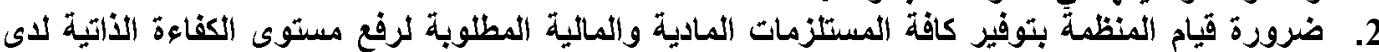

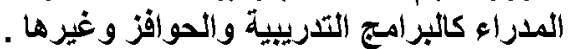

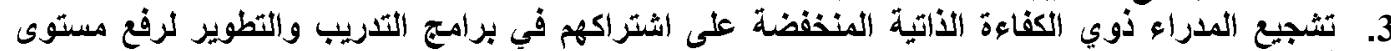

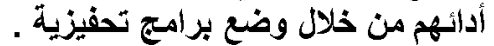
4. ضرورة قيام المنظمة باستقطاب المدراء الأي يتمتعون بكفاءة ذاتية مرتفعة وذلك لفرض تعزيز أداء المنظمة كکل. .

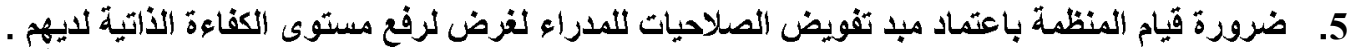

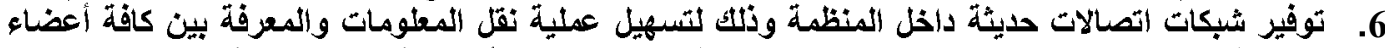
المنظمة وذلك لفرض تصسين مستوى الكفاءة الأتية للمدراء وكنلك أداء الإقفراد العاملين فيها.

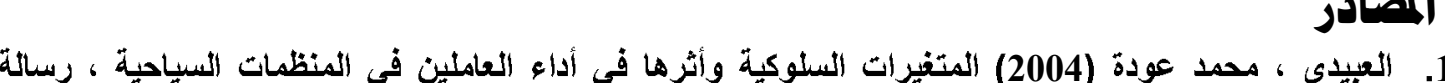

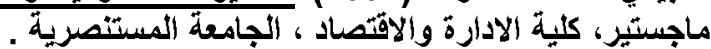

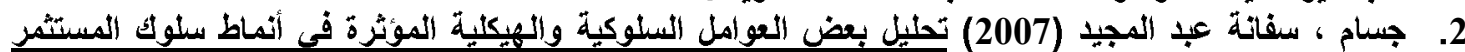

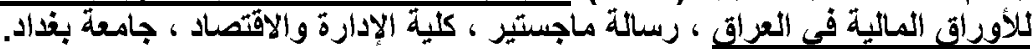

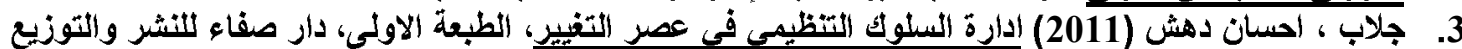

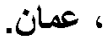
4. صالح ، عادل حرحوش و داغز ، منق محد (2000) نظرية المنظمة واللئوك التظبيس ، الطبعة الاولى ، دار

5. Davis, Keith (1988) Human Relations at Company work , New York. الكتب للطباعة ، بغداد.

6. Diehl, A. \& Pront, M. (2002) Effects of Posttraumatic Stress Disorder and Child Sexual Abuse on Self-Efficacy Development American Journal of Orthopsychiatry.

7. Furlong, M. (1996) Esteem Building Versus Publishment: The Effect of Self-Esteem Group Counseling on the Behavior of Junior High School Students Degree , Memorial University of New Found Land, Canada.

8. Jackson, A. (2000) Maternal Self-Efficacy and Children's Influence on Stress and Parenting Among Single Black Mothers. Journal of Family Issues.

9. Sanda , Mohammed- Aminu (2011) Managerial Self-efficacy and Discretionary Behavior Improving Work Environment for Small Firm Performance, Journal Information Management and Business Review . 
10. TIERNEY, PAMELA \& FARMER ,STEVEN M. (2002) CREATIVE SELFEFFICACY: ITS POTENTIAL ANTECEDENTS AND RELATIONSHIP TO CREATIVE PERFORMANCE, Journal Academy at Management formal.

11. Bin, Hu \& Shingling, Dong (2006) QUALITATIVE SIMULATION FOR MANAGER SELECTION DECISION-MAKING BASED ON MANAGERIAL SELF-EFFICACY, Proceedings of the 2006 Winter Simulation Conference .

12. Ramlall, Sunil J.( 2006) Identifying and Understanding HR Competencies and their Relationship to Organizational Practices , Journal Applied Research.

13. Switzer, Kelly C. \& Nagy, Mark S. \& Mullins, Morell E. (2005) The Influence of Training Reputation, Managerial Support, and Self-Efficacy on Pre-Training Motivation and Perceived Training Transfer, Journal Applied H.R.M. Research,

14. Izquierdo, Edgar \& Buelens, Marc (2008) COMPETING MODELS OF ENTREPRENEURIAL INTENTIONS: THE INFLUENCE OF ENTREPRENEURIAL SELF-EFFICACY AND ATTITUDES, USA. Este artículo obtuvo el Best Paper Award, 3rd rank.

15. $\underline{\text { www.taalliance.org , (2002) Functional Behavioral Assessment and }}$ PositiveInterventions: What Parents Need to Know 


\title{
The Reflection of self competency of the managers in their behavior
}

\begin{abstract}
This research aims to measure the effect of Self competency of the Managers in their behavior from the view point of the working individual in the organization since the behavior of managers is considered to be one of the essential variables in the organization which can affect the performance and the commitment of the working individual. the questioners was used to gather the data and the Iraqi Rail Road co. was the field of the study . and a random sample of (36) individual of the subordinates of the managers society of the study and used the (SPSS) statistical program was used in the analysis of the data of the research . the findings refer to the existence of a clear effect for the Self competency in their behavior toward their subordinates, therefore the research condoled that there is an audience for effective relationship between the self competency of the manager in their competency and their behavior therefore the research recommended for the necessity for increasing the cancers on the organization in studying the subject related to the managers which are represented in their perditions and behavior and the most influential variables becomes because of their great effects in the process of motivating the employees and increasing their driver in the job and improving the manner of human resources in the organization.
\end{abstract}

Key Words : Managers, Self Competency, behavior, employees, organization , leadership. 